\title{
The COVID-19 pandemic and student engagement in online learning: The moderating effect of technology self-efficacy
}

\author{
Yaw Owusu-Agyeman ${ }^{1}$, Juliana Serwaa Andoh ${ }^{2}$ and Ernestina Lanidune ${ }^{3}$ \\ ${ }^{1}$ University of the Free State, South Africa (ORCID: 0000-0001-6730-5456) \\ ${ }^{2}$ Kwame Nkrumah University of Science and Technology, Ghana (ORCID: 0000-0003-4766-2469) \\ ${ }^{3}$ Cape Coast Technical University, Ghana (ORCID: 0000-0001-8447-6994)
}

\begin{abstract}
This study examines the moderating effect of technology self-efficacy on the relationship between online learning and student engagement in a higher education setting. A survey was used to gather data from participants $(n=425)$ who were sampled from a population of registered students in a Technical University in Ghana. The data gathered were examined using hierarchical regression analysis. Results revealed that, technology self-efficacy strengthens 1) the positive relationship between online learning environment and student engagement; and 2) the positive relationship between instructional resources and student engagement. Secondly, the results revealed that the type of device used by students in the online learning environment has a positive and significant effect on student engagement. Conversely, findings of the current study show that while gender has a negative but significant effect on student engagement, age and academic discipline have insignificant effect on student engagement in the online learning setting. These findings among others lead the authors to propose ways that future studies could examine how technology self-efficacy, learning devices, instructional resources, institutional support systems and the online learning environment could be developed to enhance effective student engagement.
\end{abstract}

Keywords: Student engagement; Technology self-efficacy; Online learning; COVID-19; Learning resources

Article History: Submitted 24 May 2021; Revised 13 November 2021; Published online 12 December 2021

\section{Introduction}

The SARS-CoV-2 (COVID-19) pandemic has created momentous challenges for educational intuitions with about 38,560,502 learners representing 2.4 percent of total learners worldwide in 10 countries still out of school due to countrywide school closures as of November 11, 2021. Not only did the COVID-19 pandemic alter the traditional and blended mode of learning to fully remote delivery (Prokes \& Housel, 2021), it also stretched the resources of countries and educational institutions. Without doubt, the COVID-19 pandemic gave rise to the use of digital tools and technology-mediated learning processes in educational institutions (Camas et al., 2021; Dhawan, 2020). In Ghana, evidence show that before the COVID-19 pandemic, very few higher education institutions (HEIs) had appraised and adopted innovative teaching and learning practices as well

\footnotetext{
Address of Corresponding Author

Yaw Owusu-Agyeman, PhD, University of the Free State. PO Box 339 Bloemfontein, 9300 South Africa.

$\bowtie$ owusuagyemany@ufs.ac.za
}

How to cite: Owusu-Agyeman, Y. (2021). The COVID-19 pandemic and student engagement in online learning: The moderating effect of technology self-efficacy. Journal of Pedagogical Research, 5(4), 119-139. https:/ / doi.org/10.33902/JPR.2021473586 


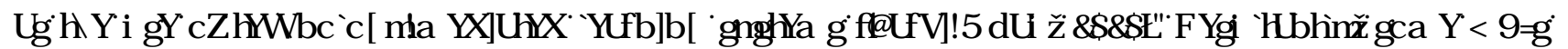

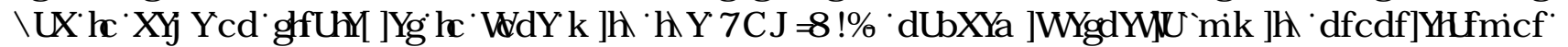

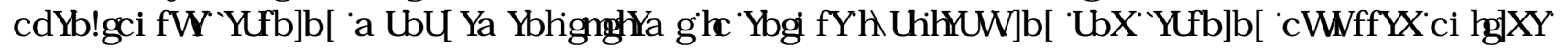

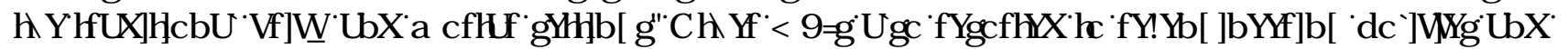

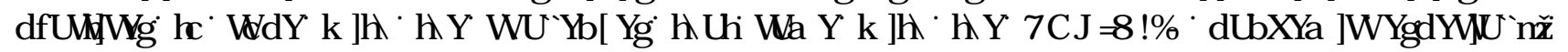

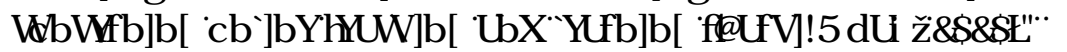

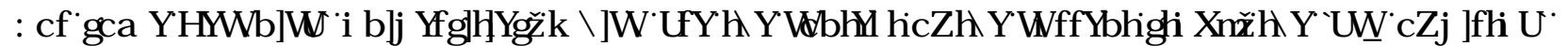

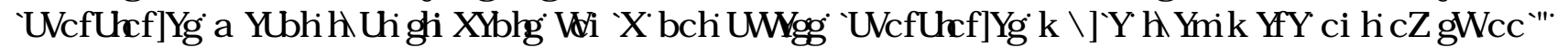

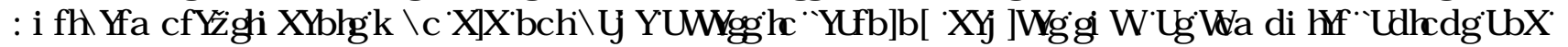

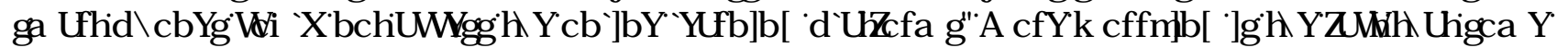

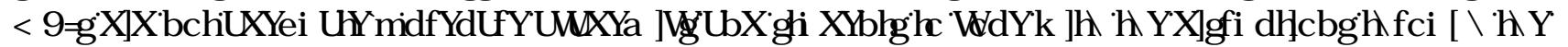

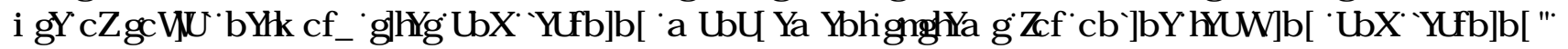
2 WHUFRQWDQWIOFOGG

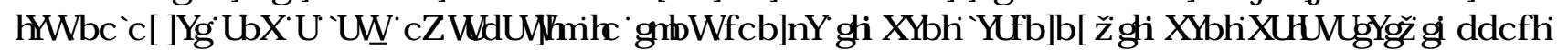

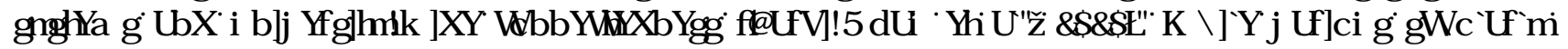

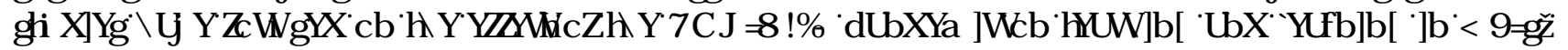

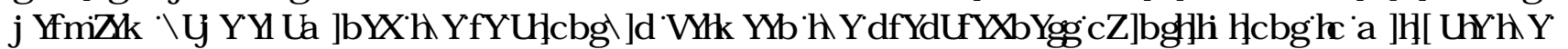

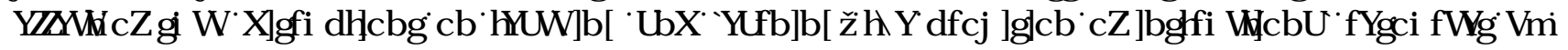
$+($, VDOGWXXGHQWD D HP HQWWD

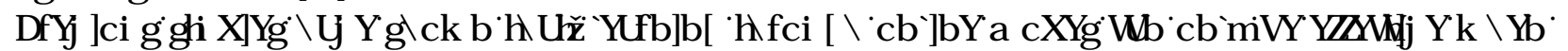

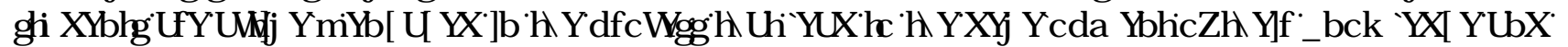

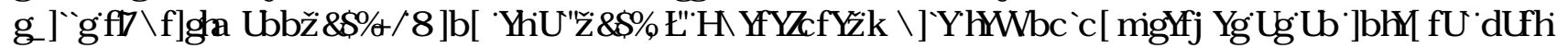

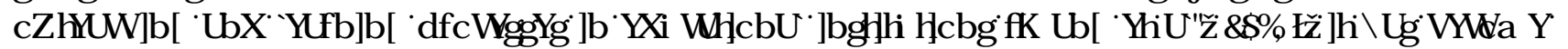

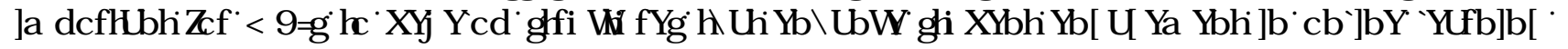

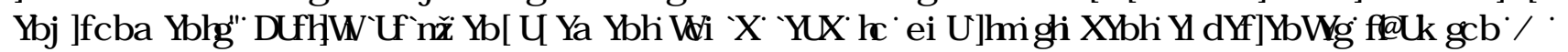

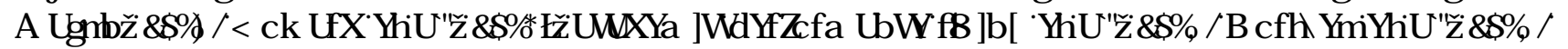

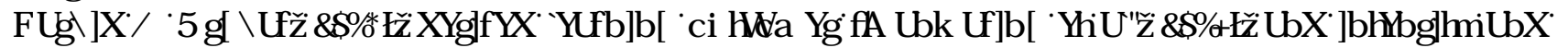

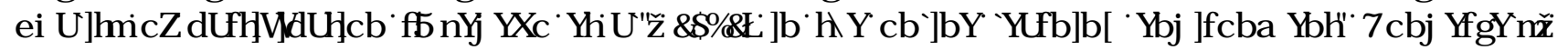

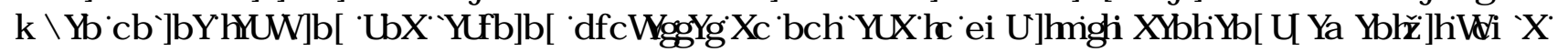

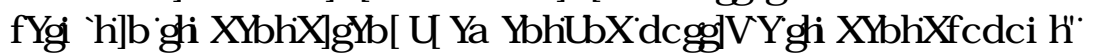

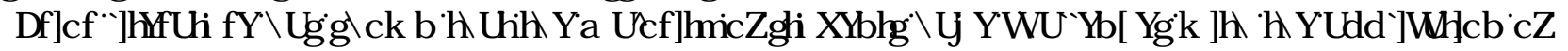

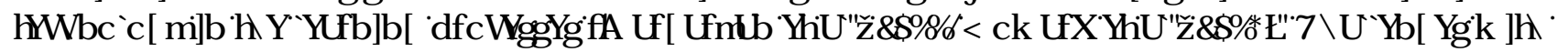

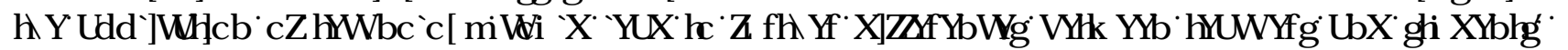

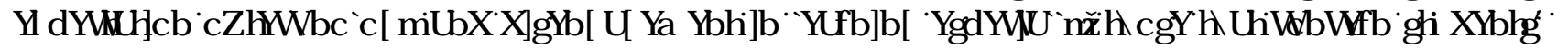

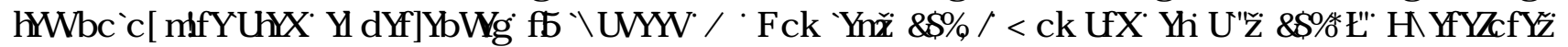

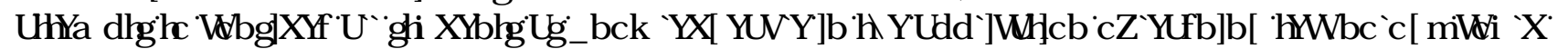

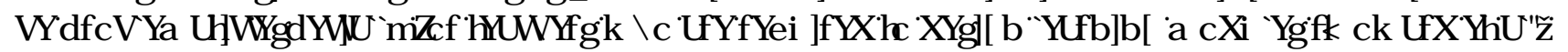

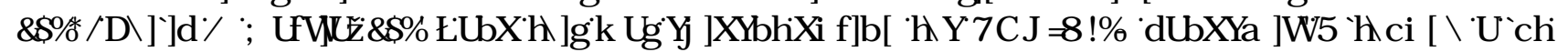

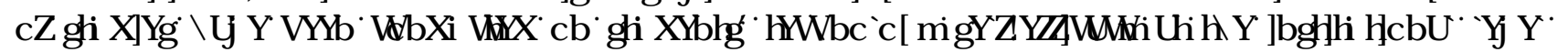
¿\&RP SHDX

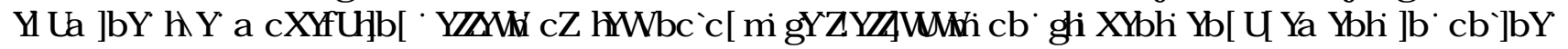

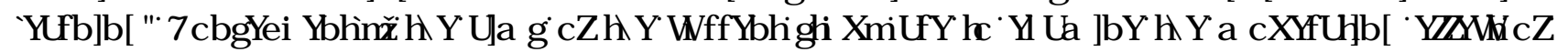

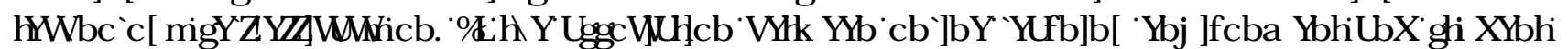

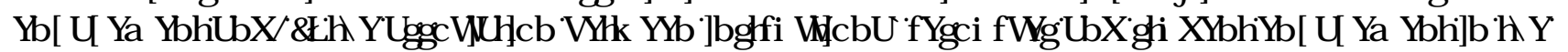
XQYHULWIII

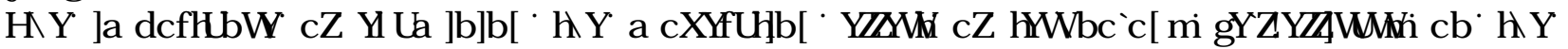

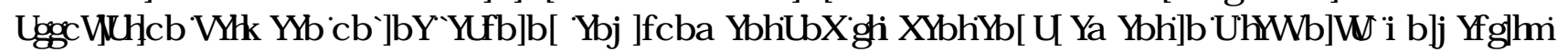

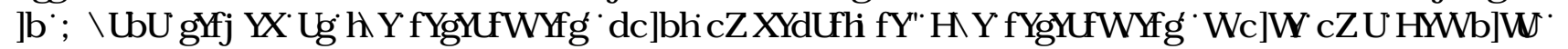

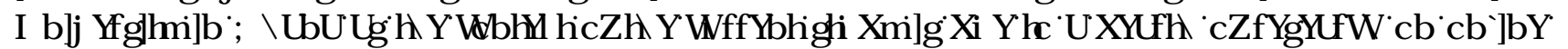

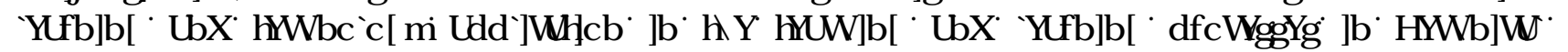

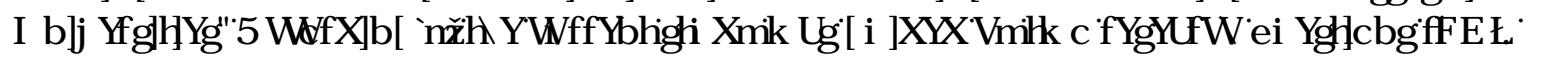




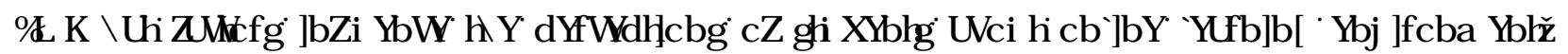

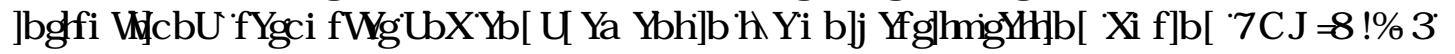

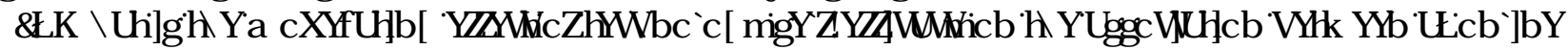

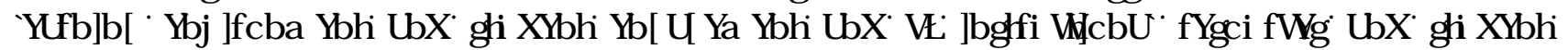

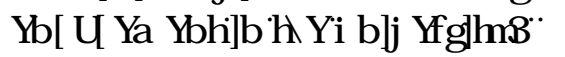

\section{IIITWG \&RQW W}

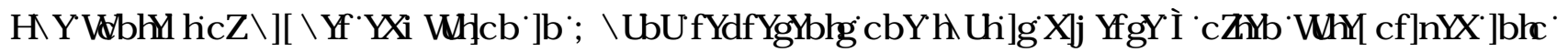

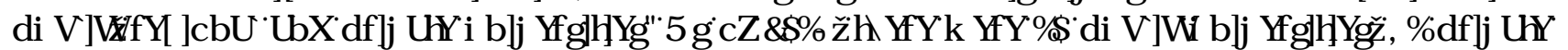

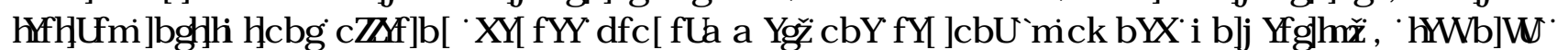

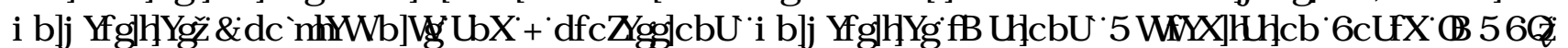

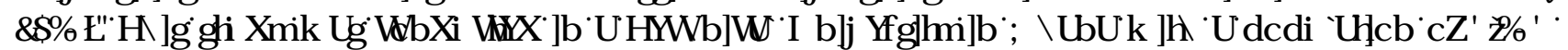

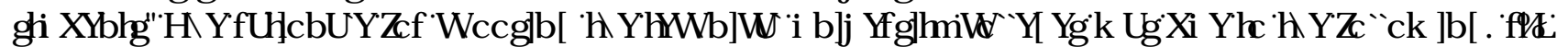

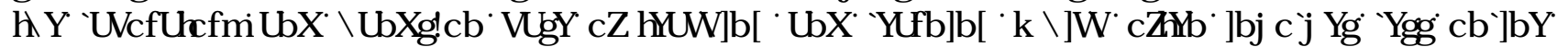

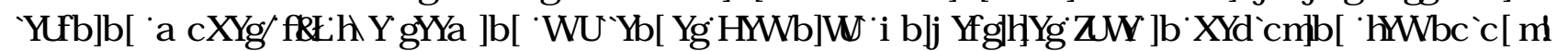

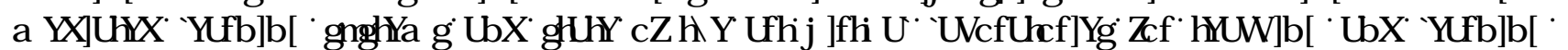

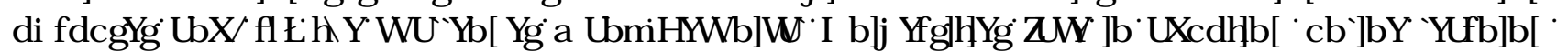

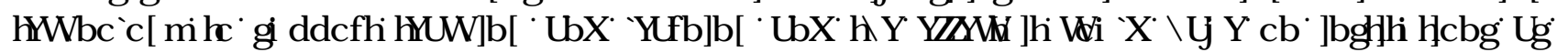

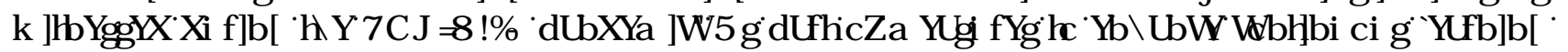

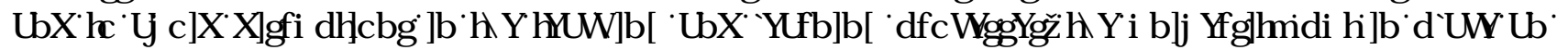

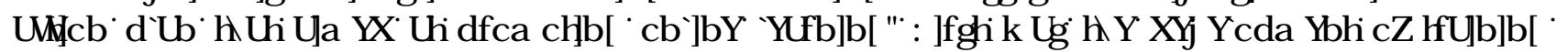

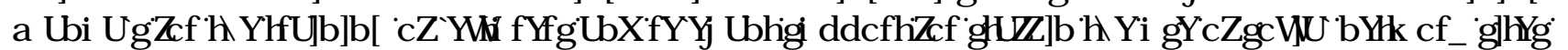

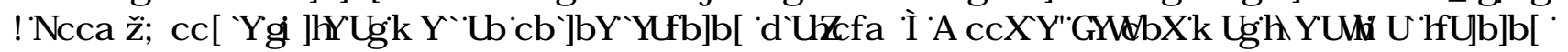

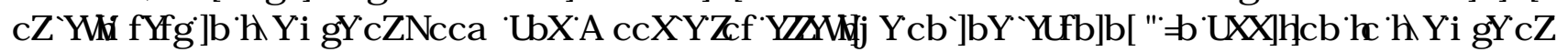

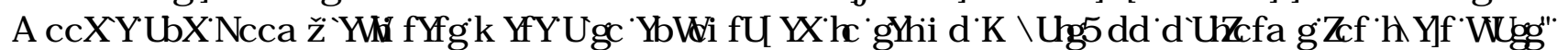

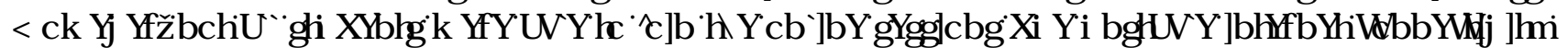

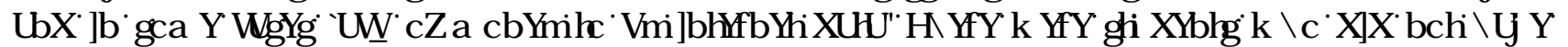

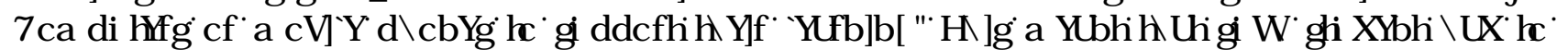

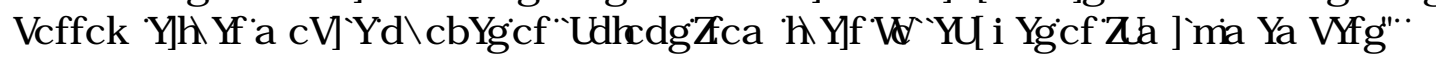

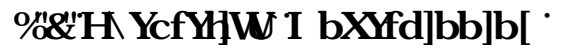

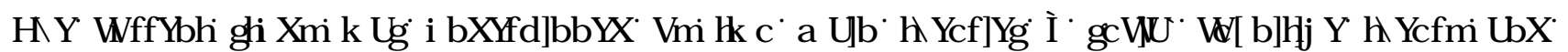

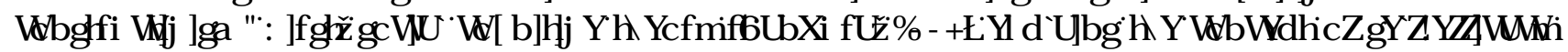

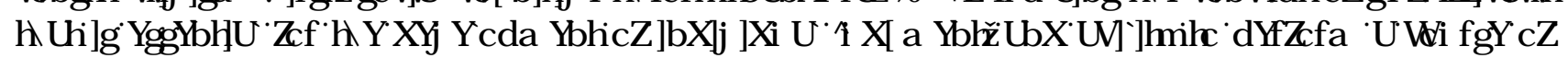

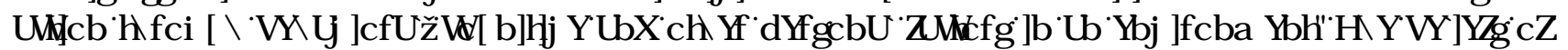

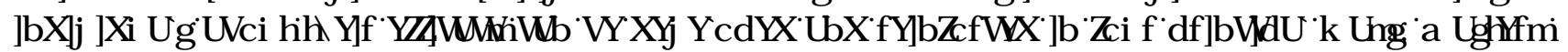

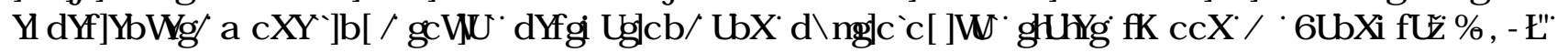

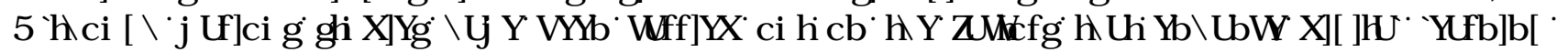

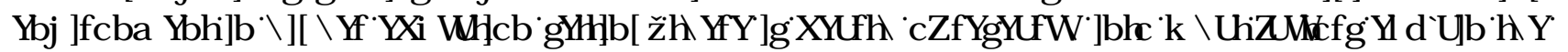

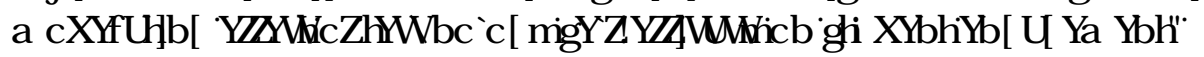

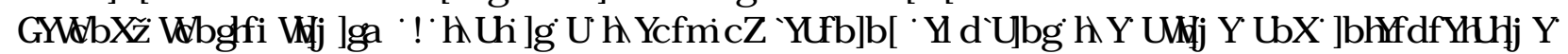

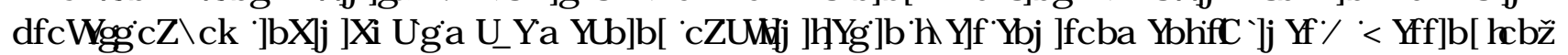

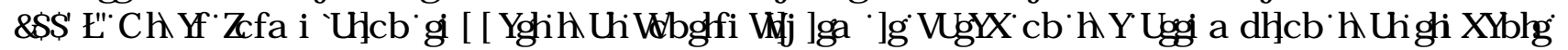

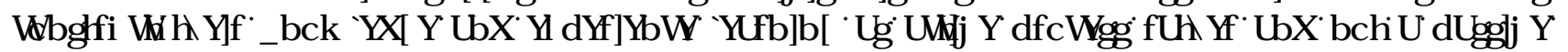

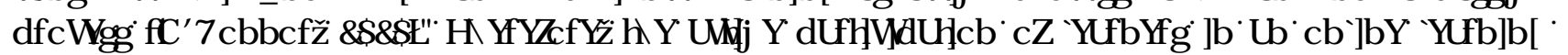

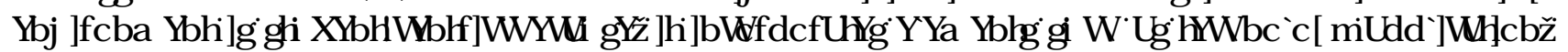

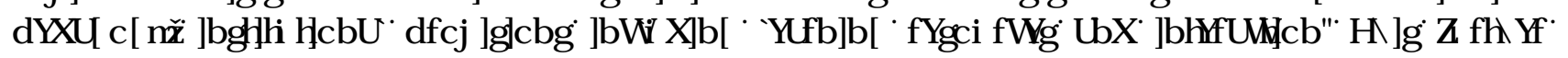

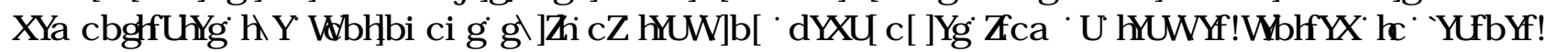

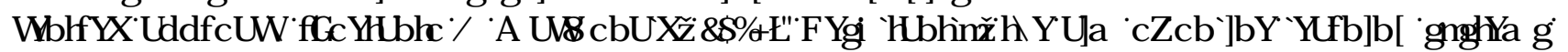

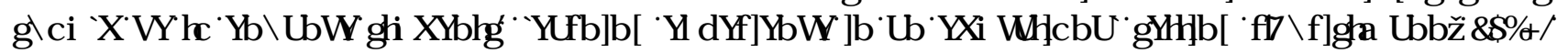

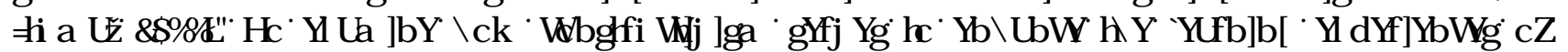

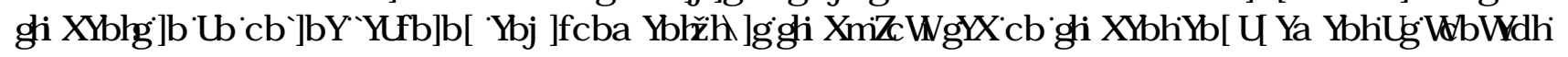




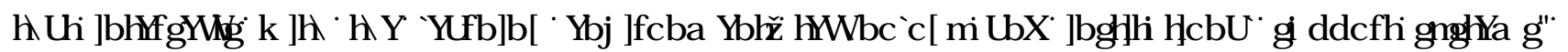

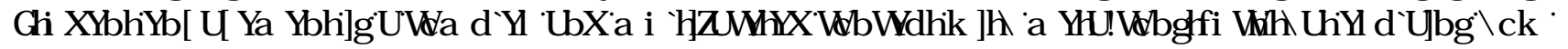

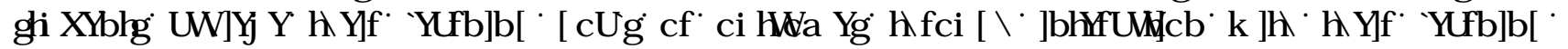

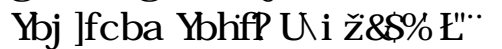

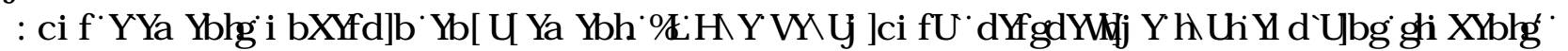

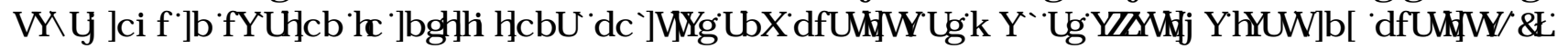

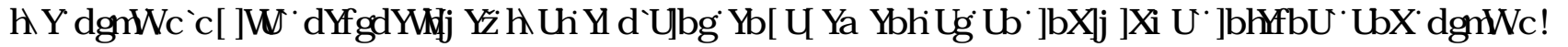

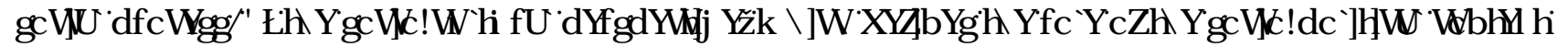

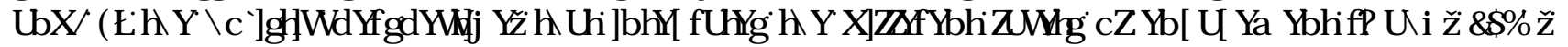

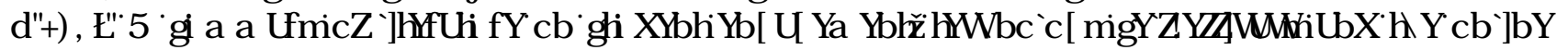

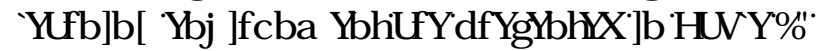

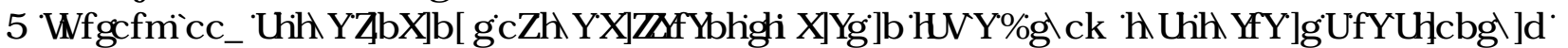

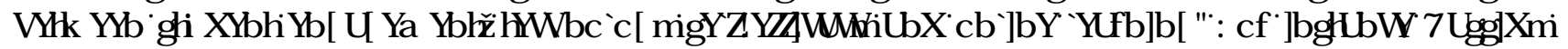

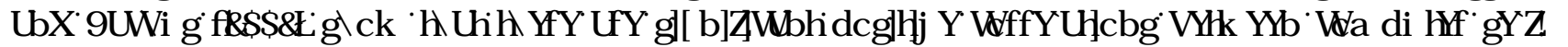

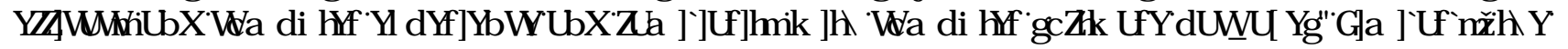
WXG IE [BHCDVIس

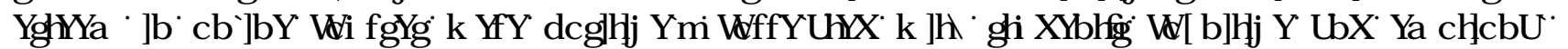

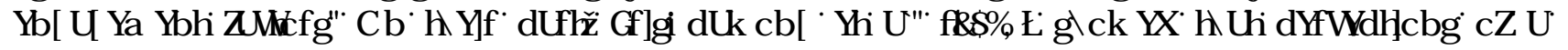

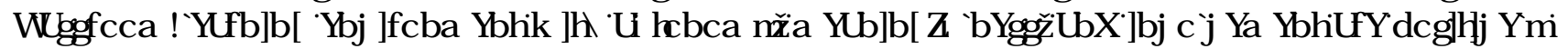

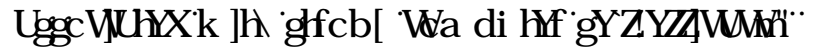

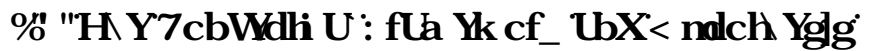

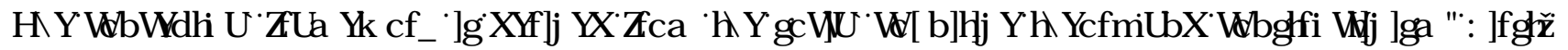

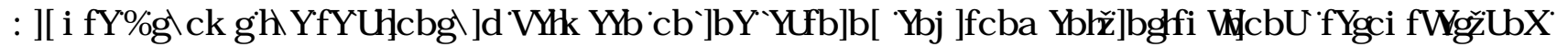

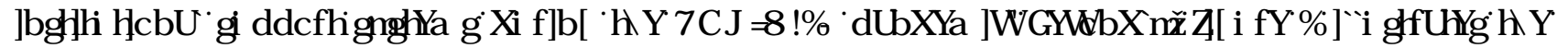

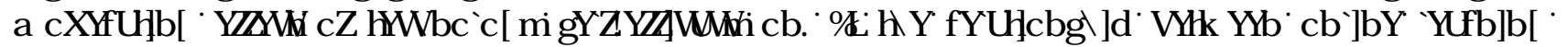

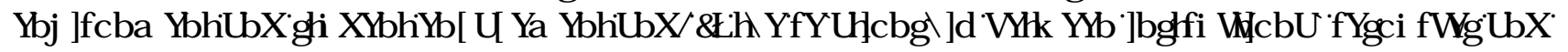

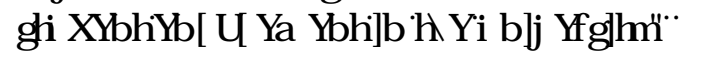

) प XUHD

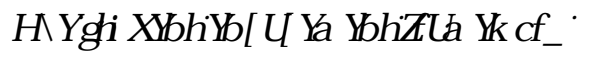

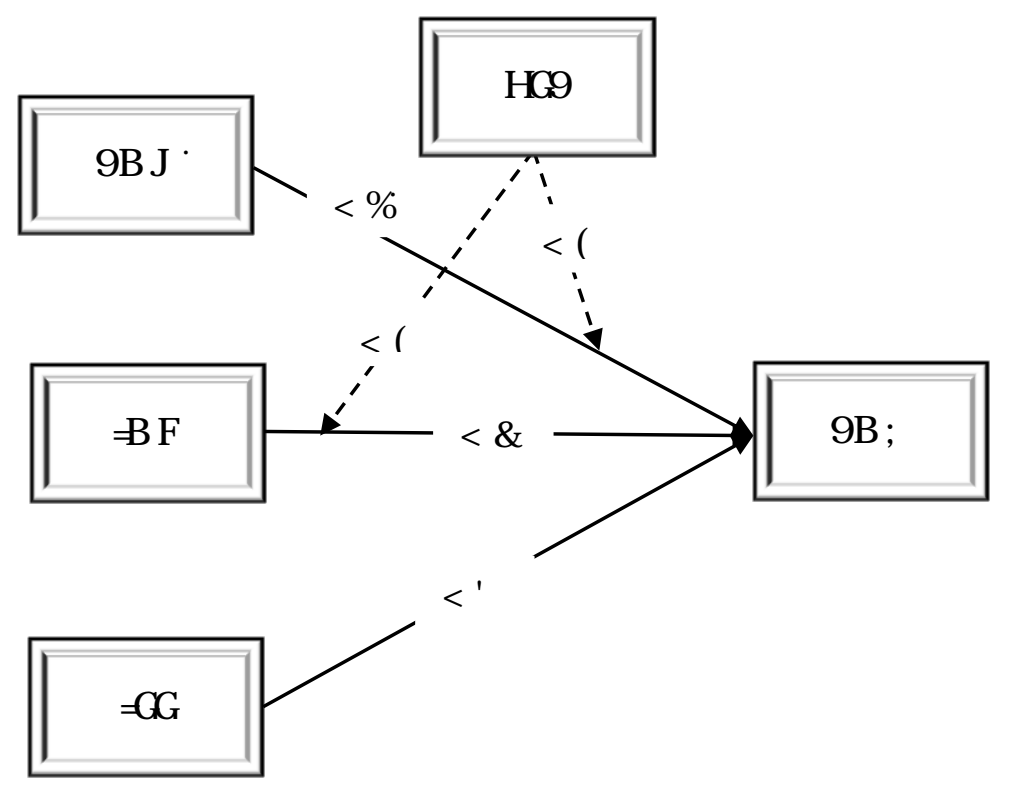

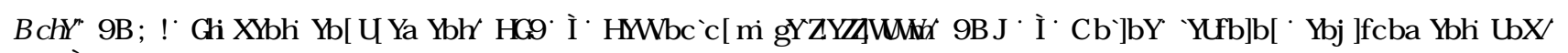

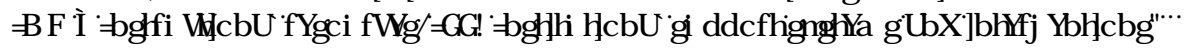




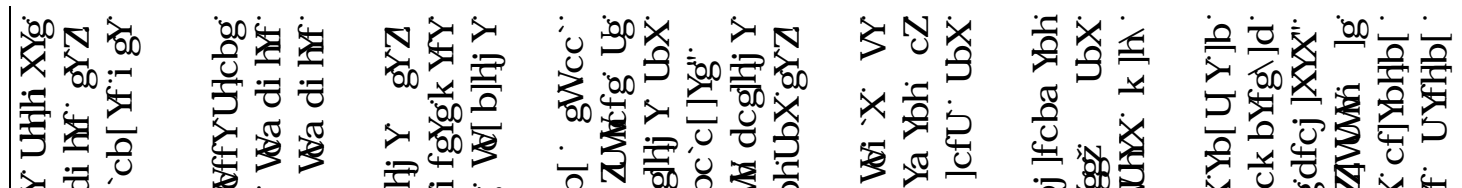

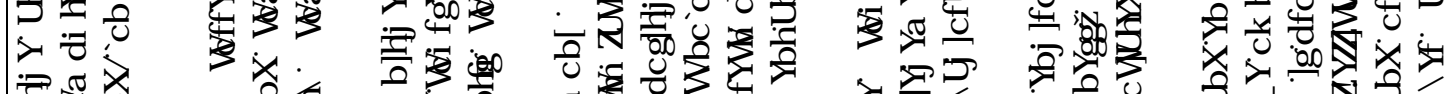
这象

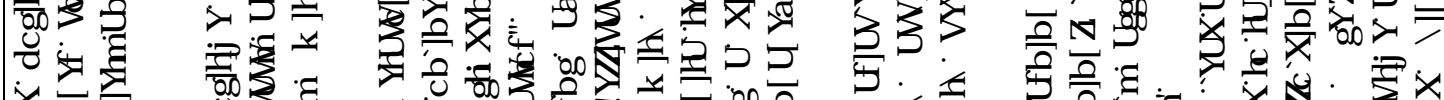

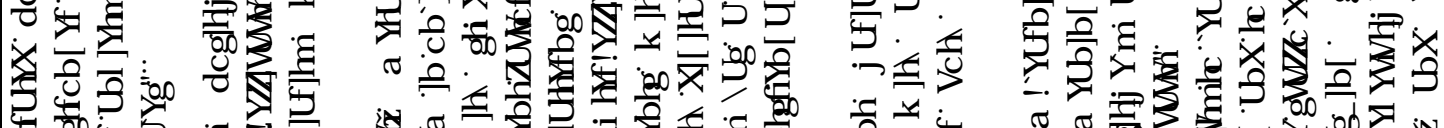

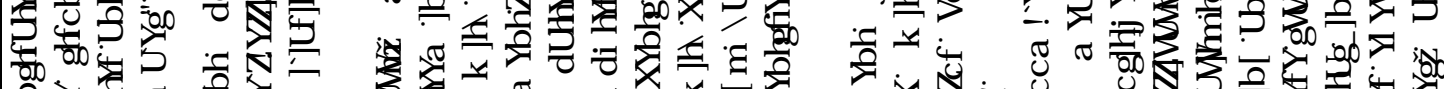

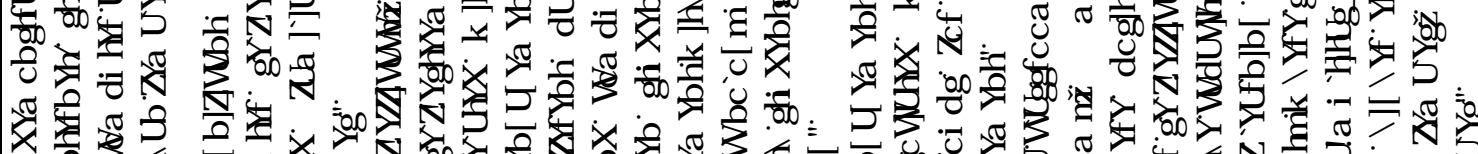

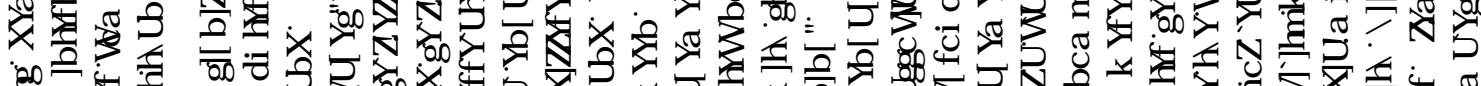

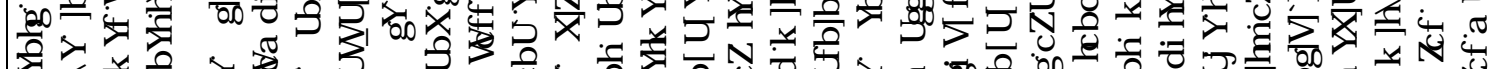

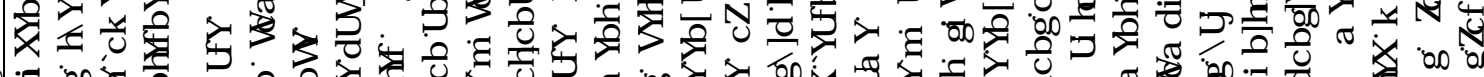

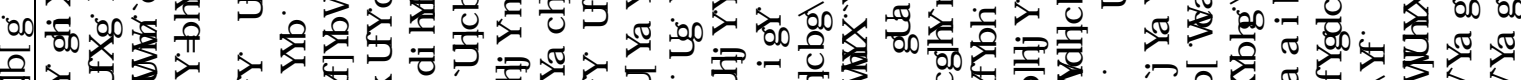

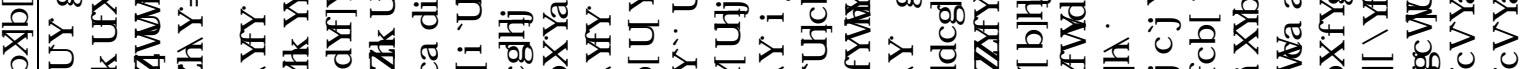

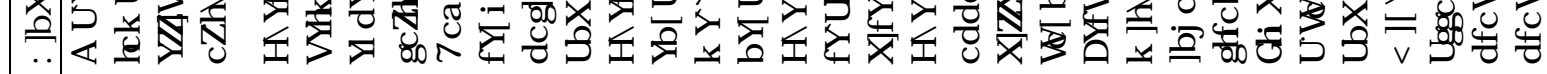

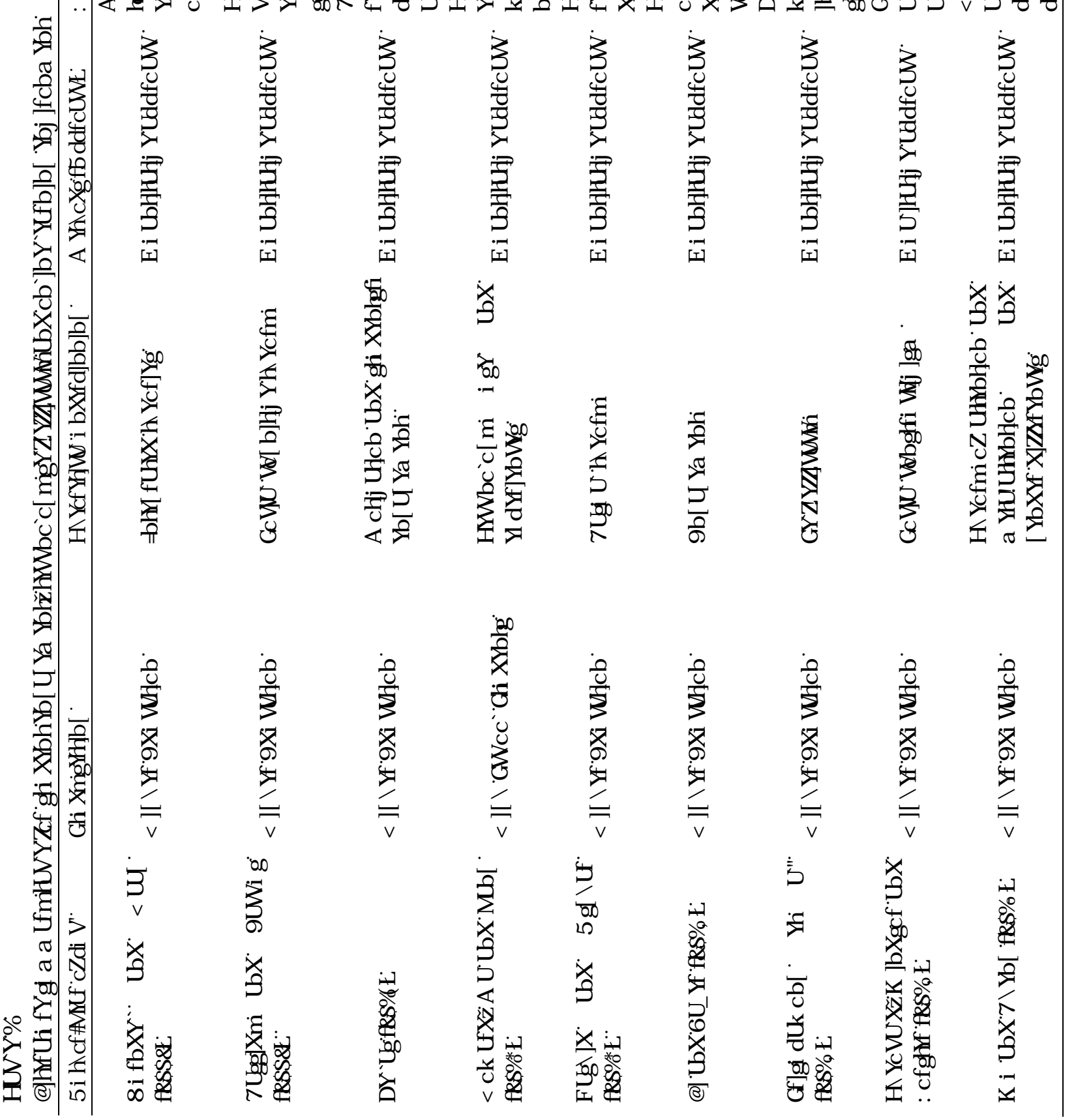




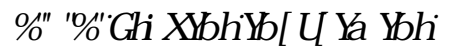

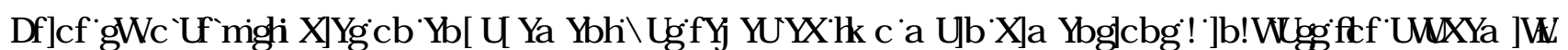

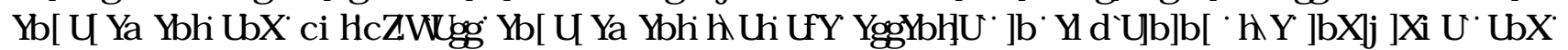

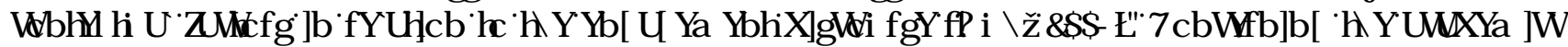
GIP HQMRQ

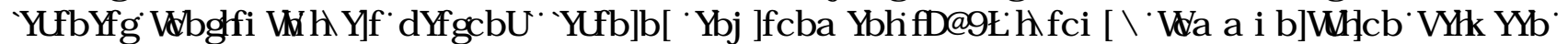

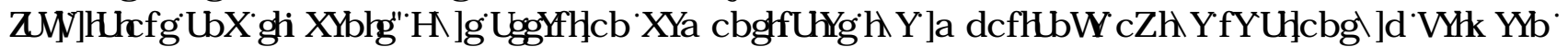

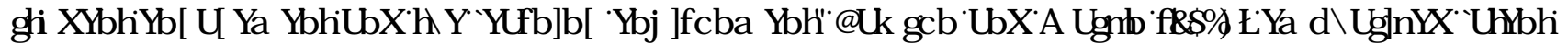

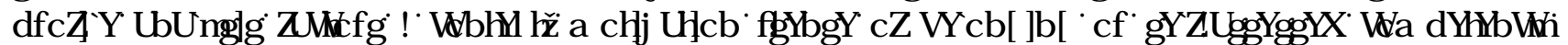

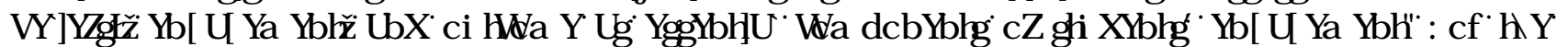

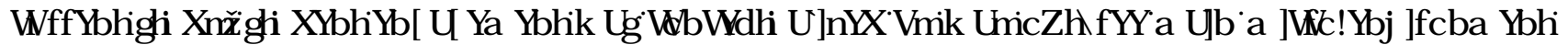

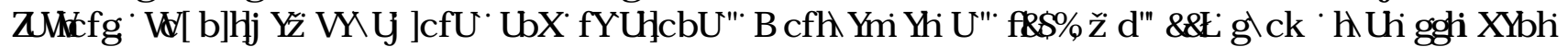

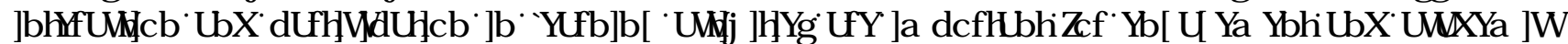

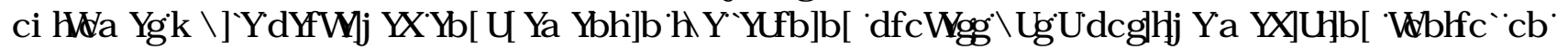
J HQHDQDFDGP IFIRXVARP HMI

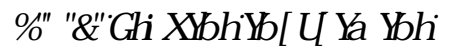

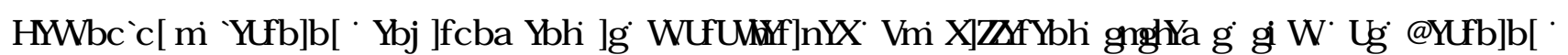

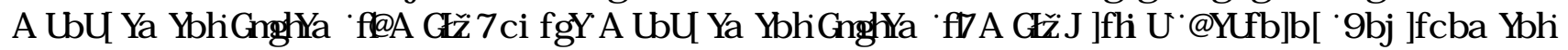

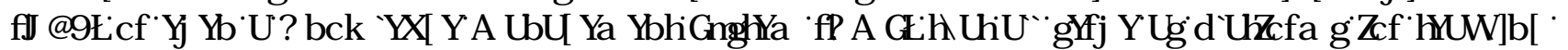

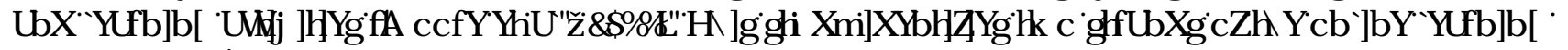

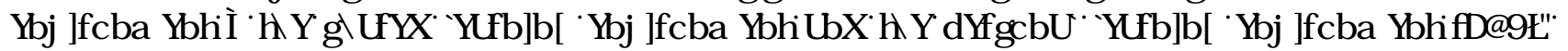

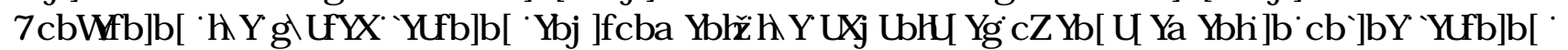

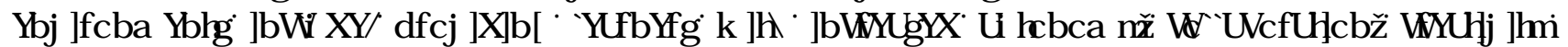

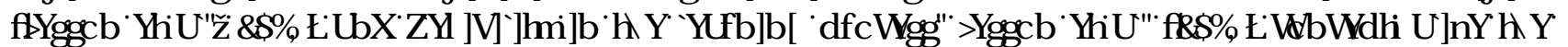

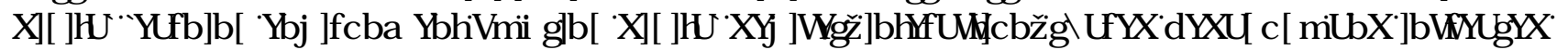

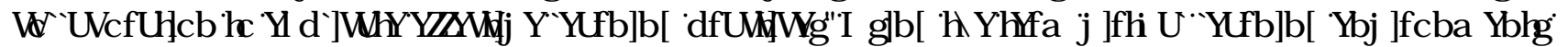

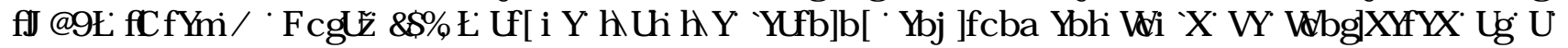

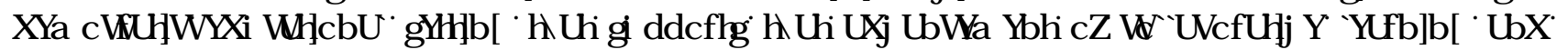

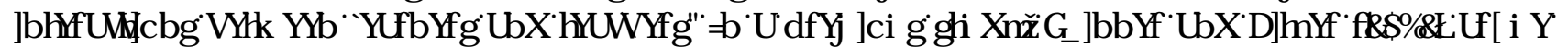

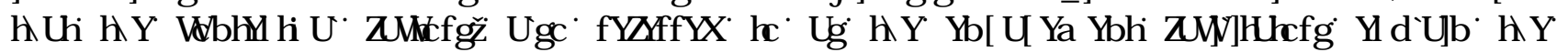

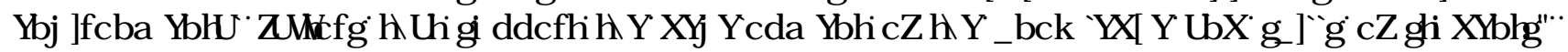

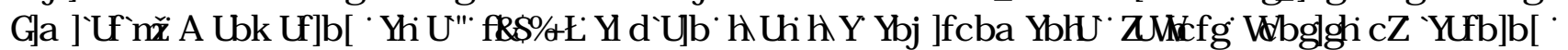

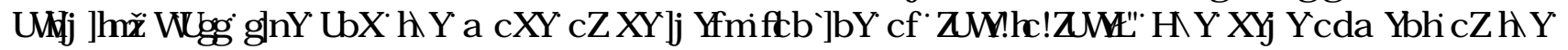

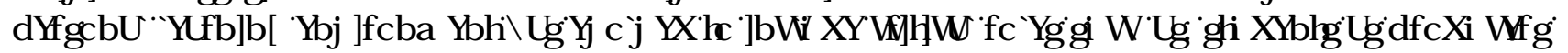

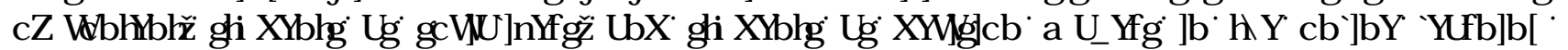

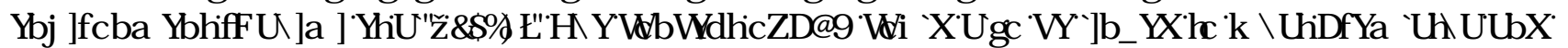
* HMRD

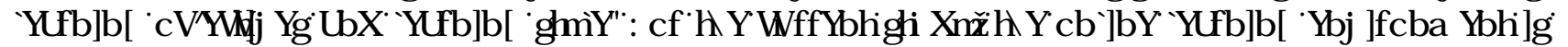

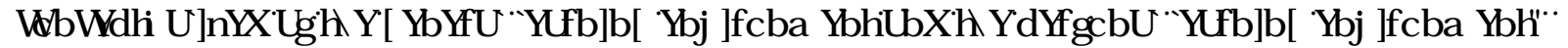

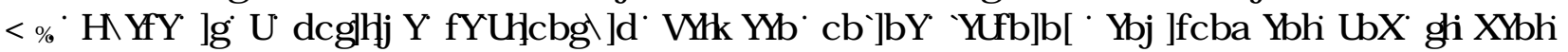

HD D HP HQMWII

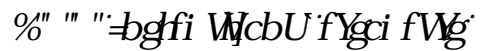

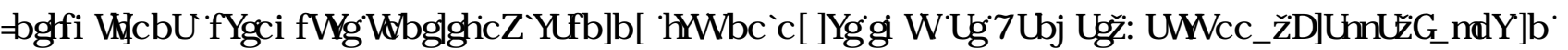

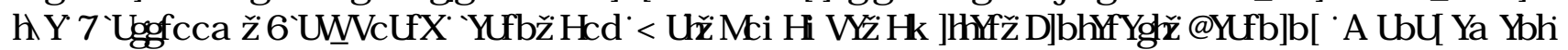

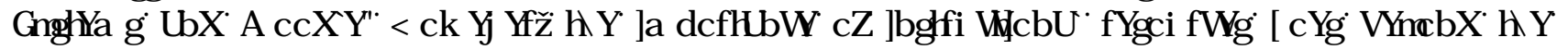

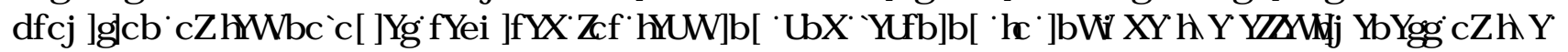

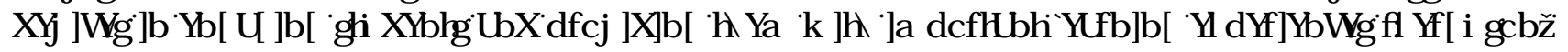

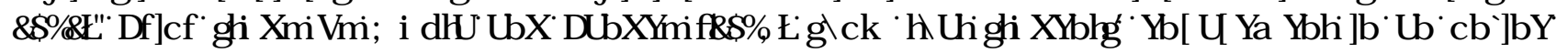

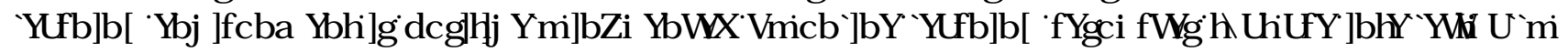




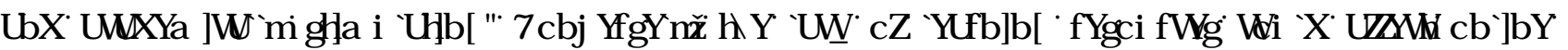

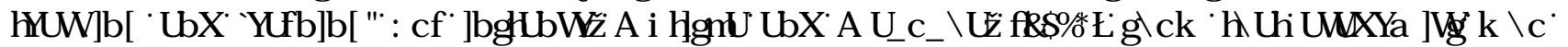

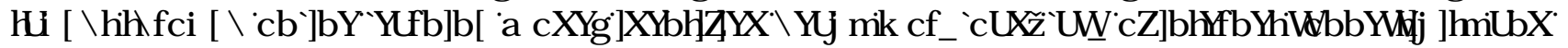

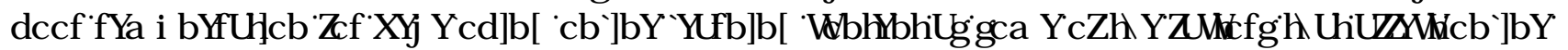

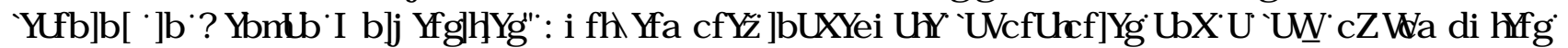

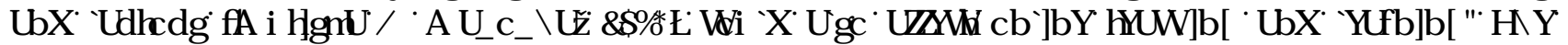

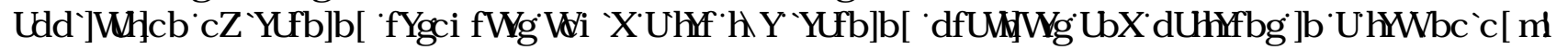

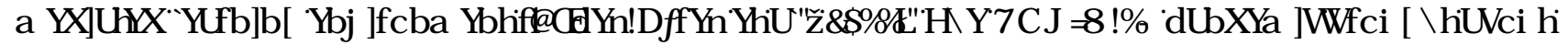

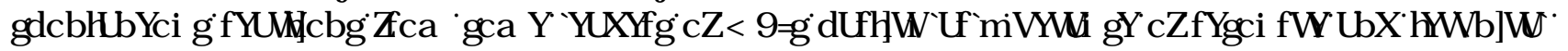
FKDOOD HMIII

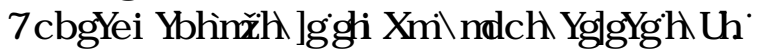

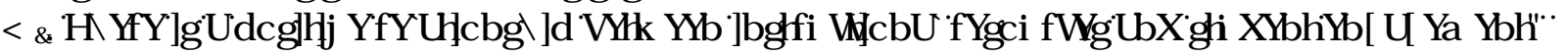

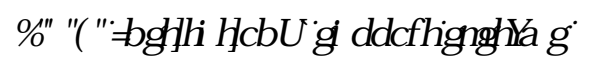

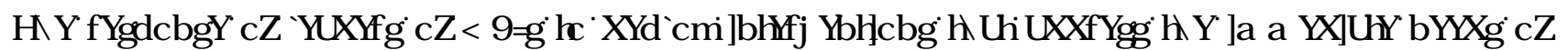

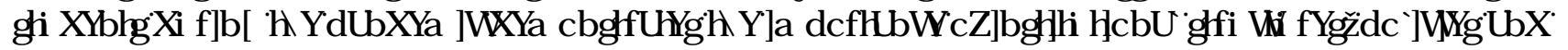

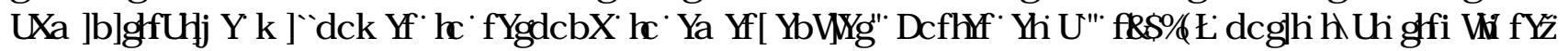

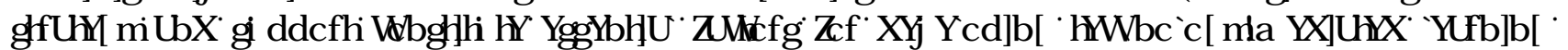

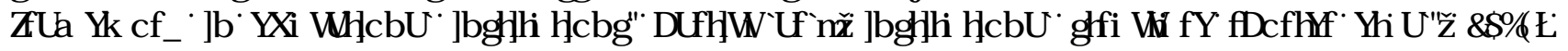

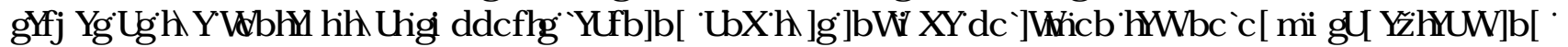

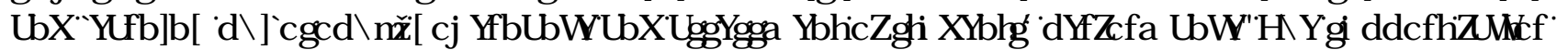

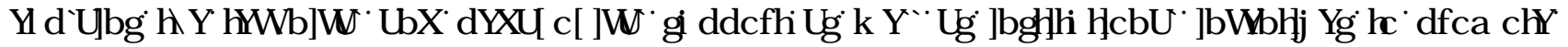

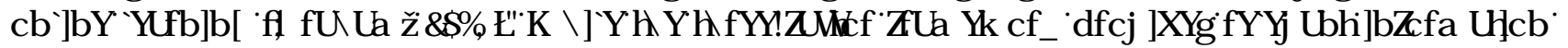

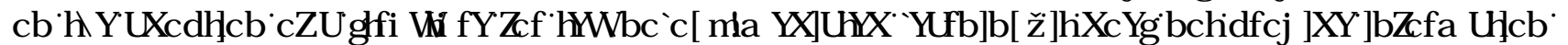

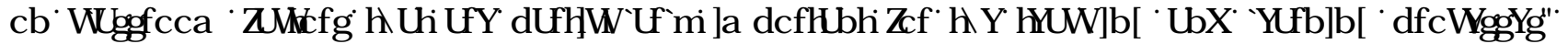

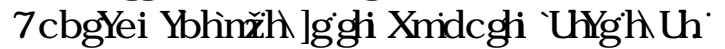

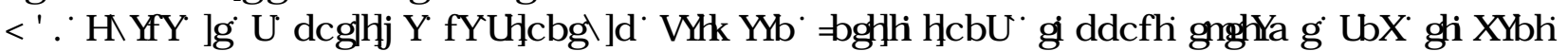
HOJ D HP HQMUII

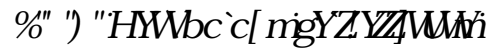

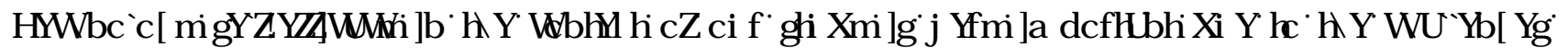

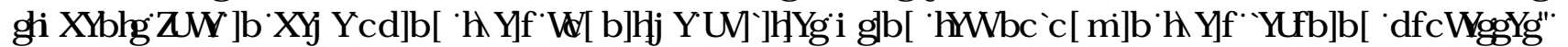

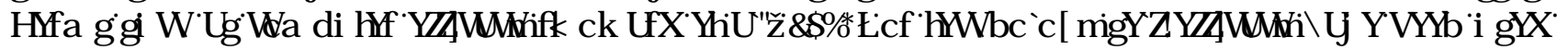

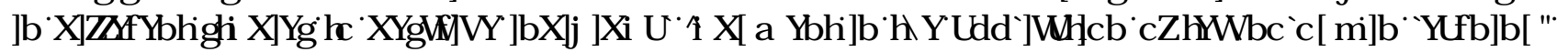

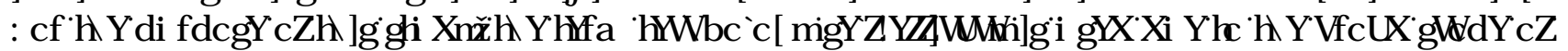

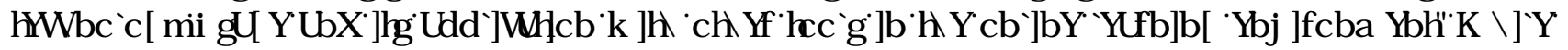

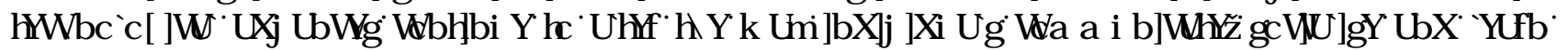

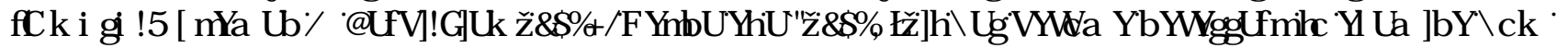

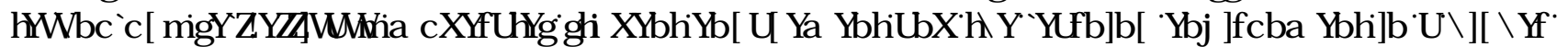

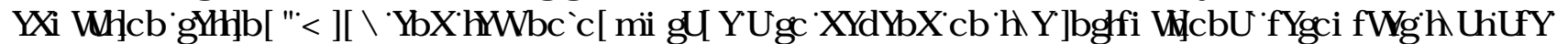

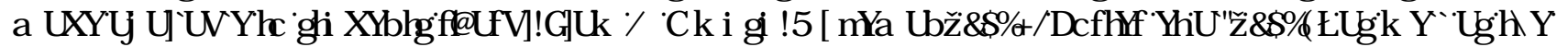

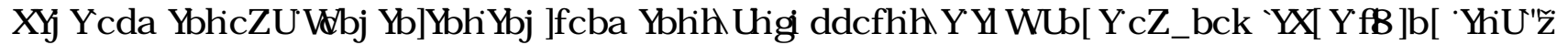

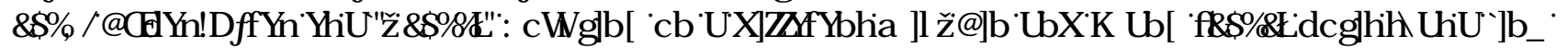

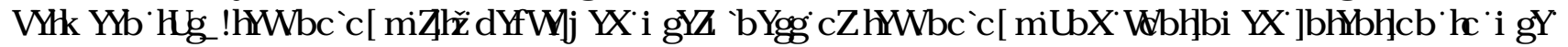

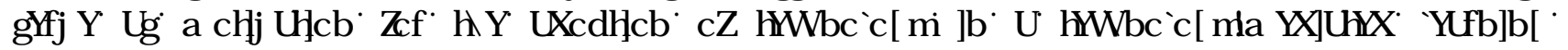

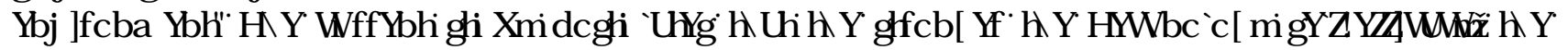

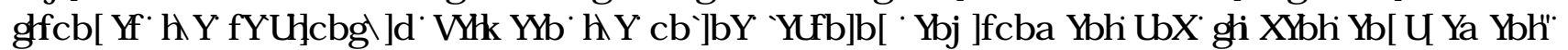

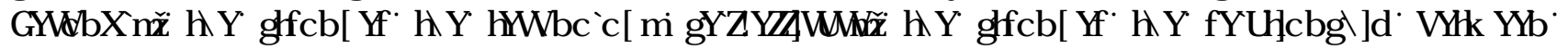

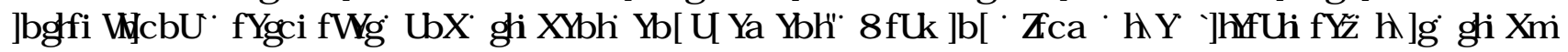
KI SRIKHM] HMYKHПRRRZ LQ 四

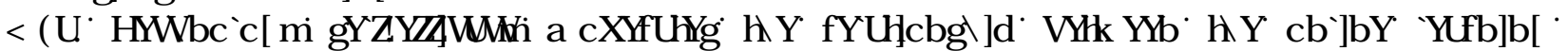
HQYLRQP HQWDQGKXXGQWFD D HP HQWMI 


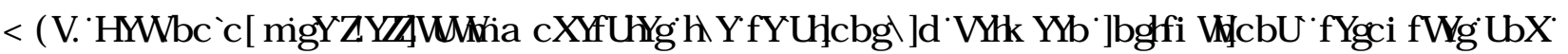
WXGHQVHD D HP HQVW

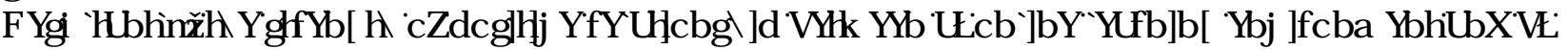

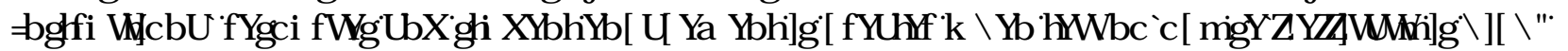

\section{IDP HMR}

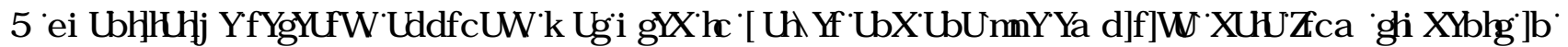

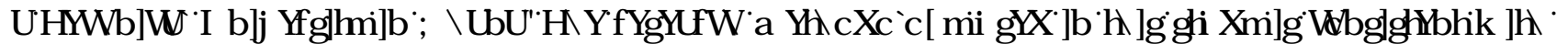

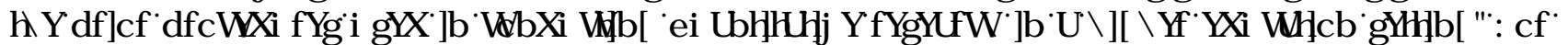
LQWDOF II+HQUH HDDQ

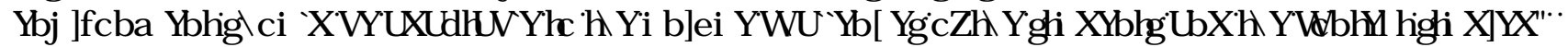

\section{口IIIBDOWASDQW}

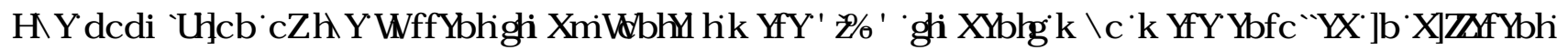

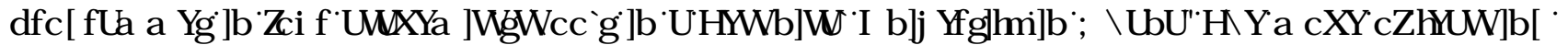

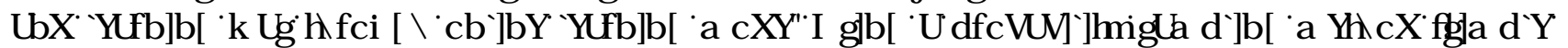

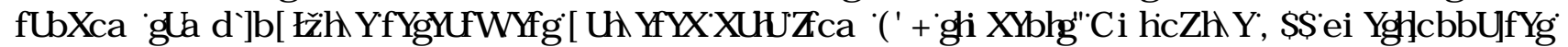

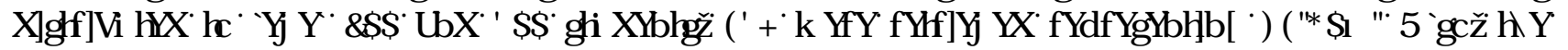

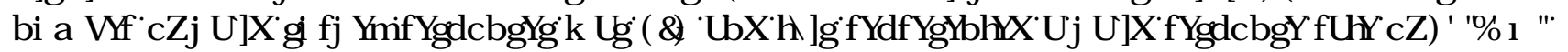

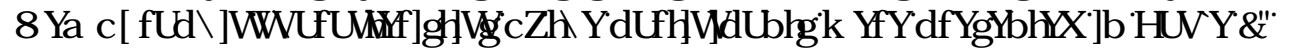

7DEOMII

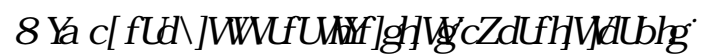

\begin{tabular}{|c|c|c|}
\hline 血 & 1 XP EUUR $\$$ SDUFSDQWIII & 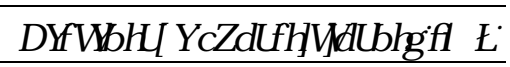 \\
\hline \multicolumn{3}{|l|}{ * HQGU } \\
\hline $0 \mathrm{DOC}$ & एण & 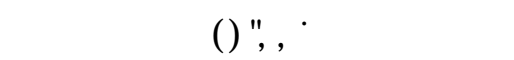 \\
\hline ) HP DOO & एण & 口प⿴囗十丁口卄 \\
\hline \multicolumn{3}{|l|}{ 6FKRQ } \\
\hline 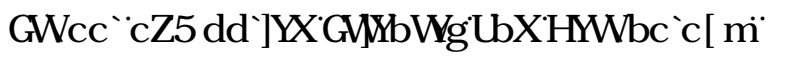 & एण & 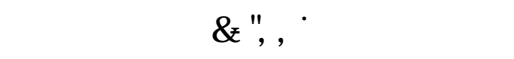 \\
\hline 6FKRRQR \$ SSQHG\$ UNG & 口田 & 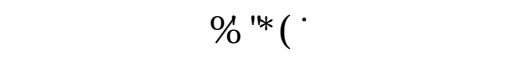 \\
\hline 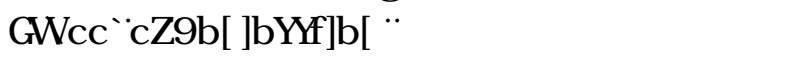 & एण & 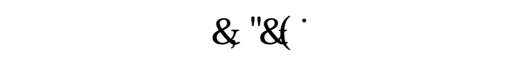 \\
\hline 6FKRRQR [SXVQHMIDQGQ DQD HP HQMБWXGHM] & $\overline{\mathrm{DT}}$ & 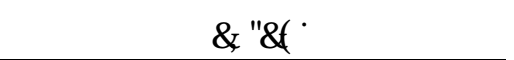 \\
\hline
\end{tabular}

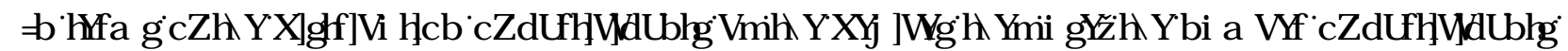

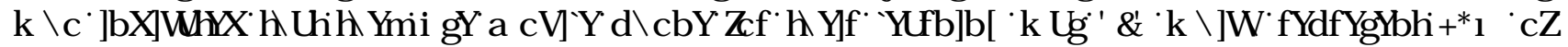

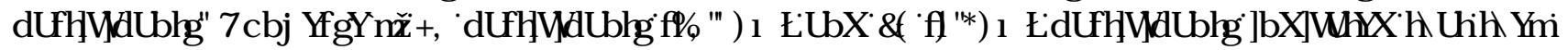

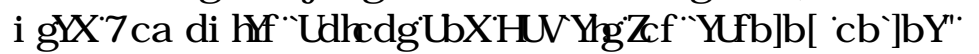

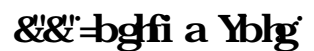

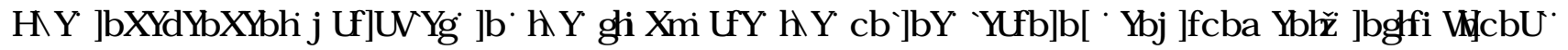

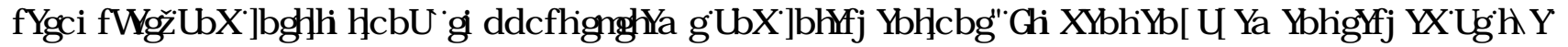

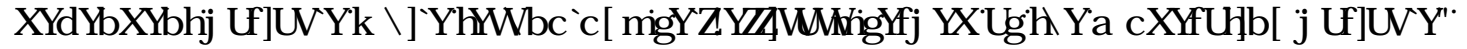

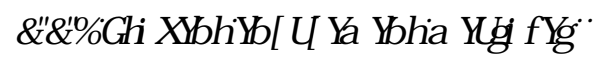

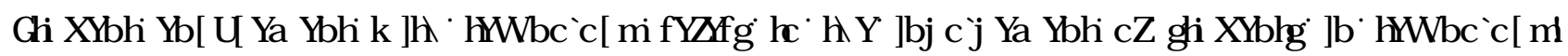

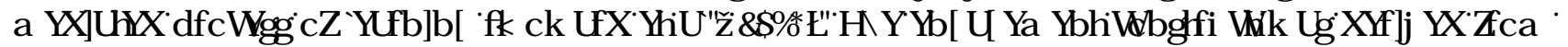

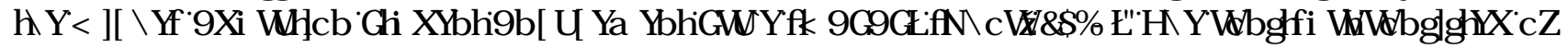

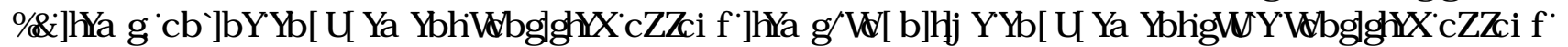

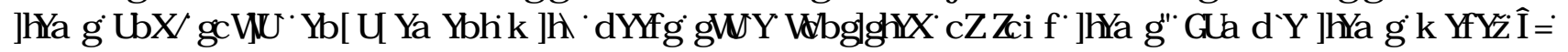




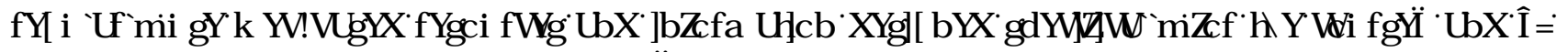

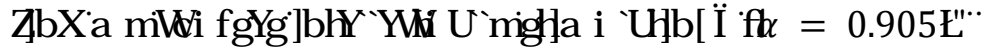

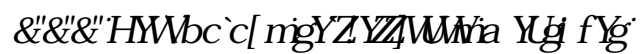

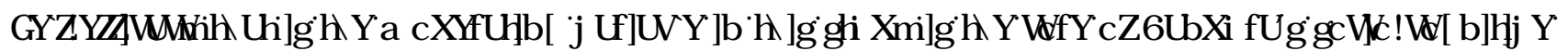

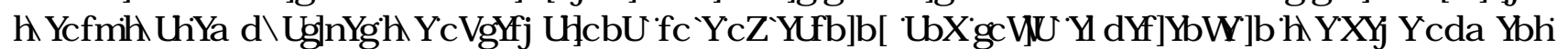

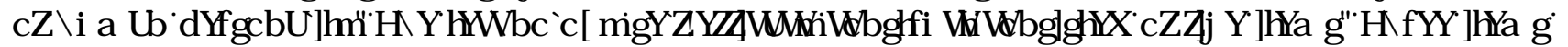

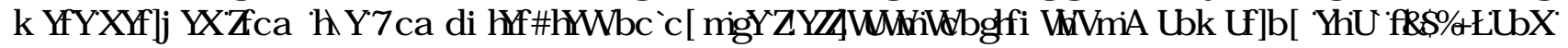

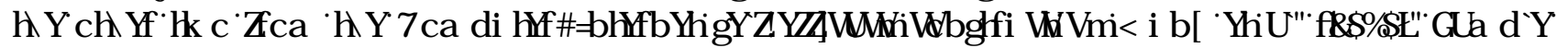

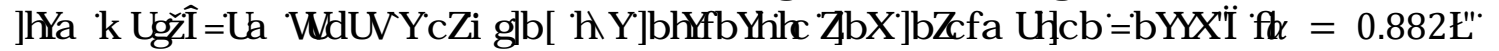

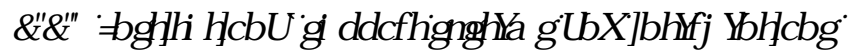

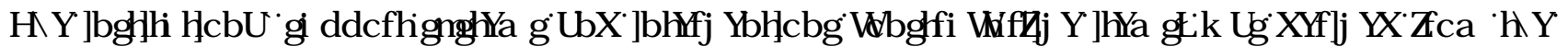

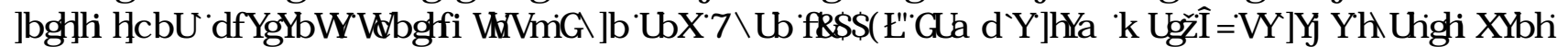

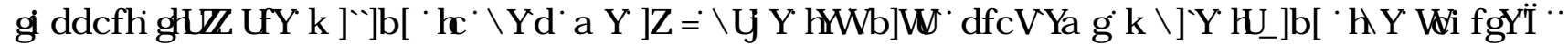

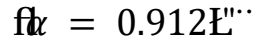

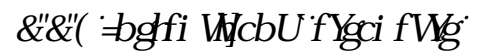

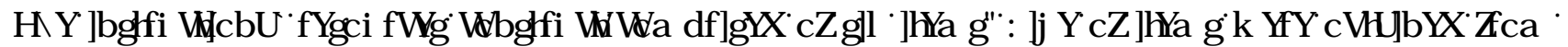

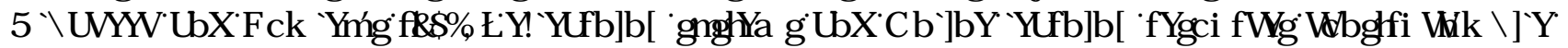

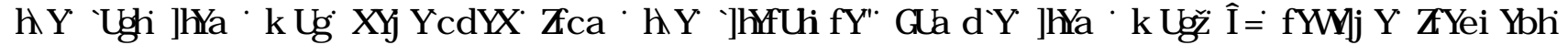

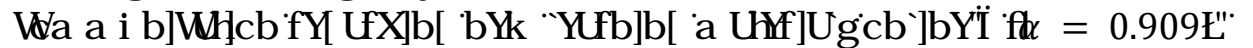

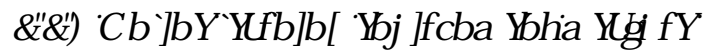

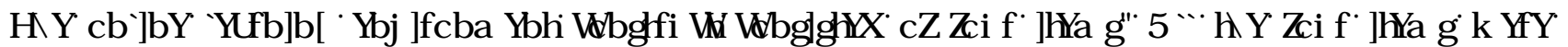

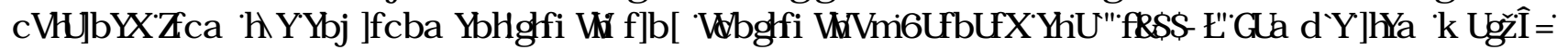

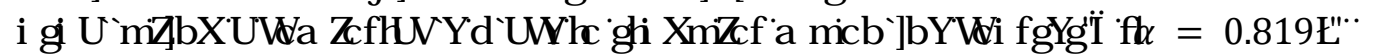

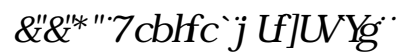

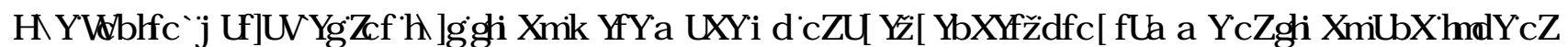

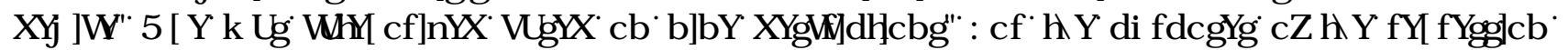

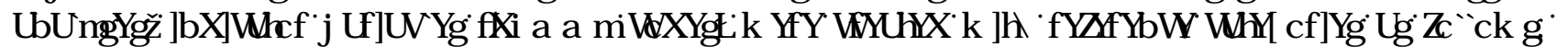

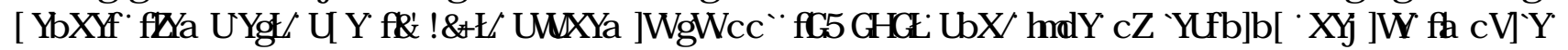

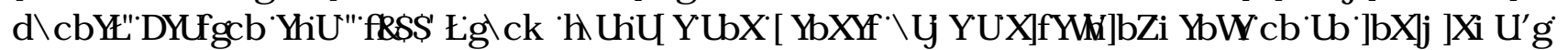

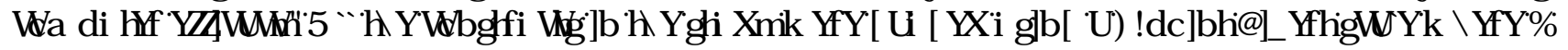

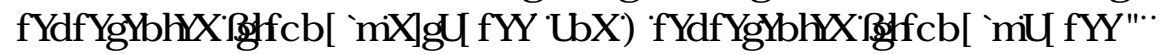

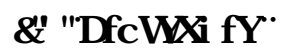

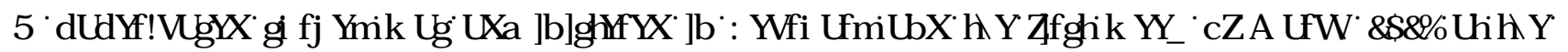

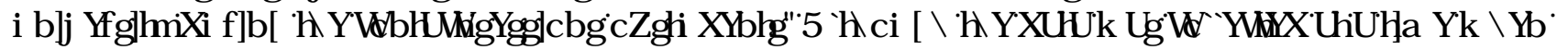

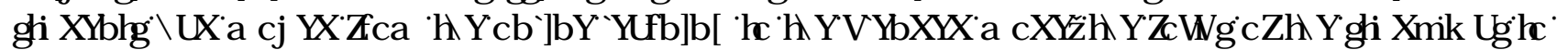

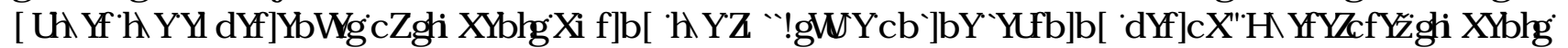

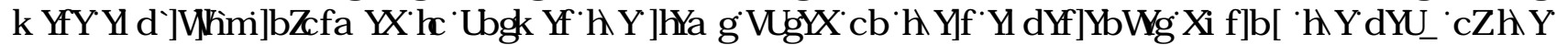

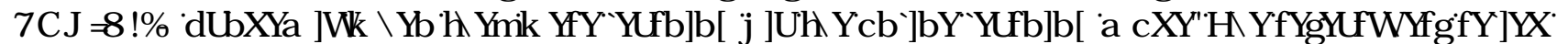

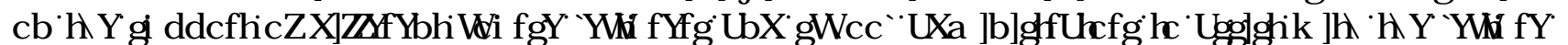

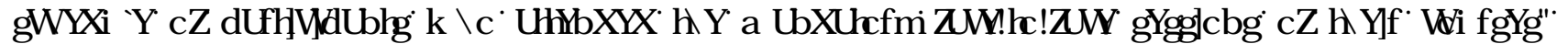

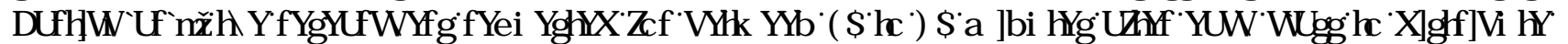

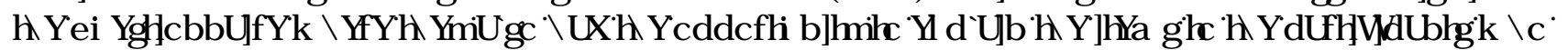

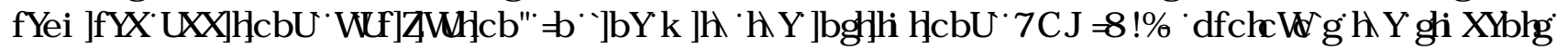

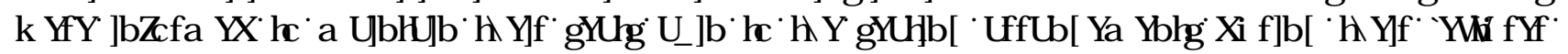

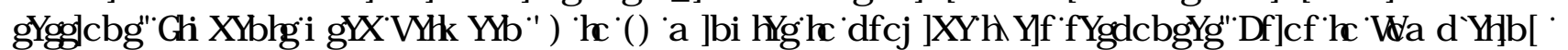

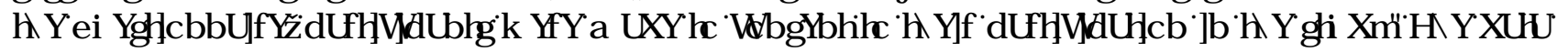




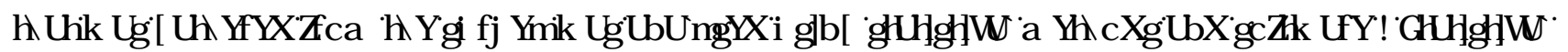

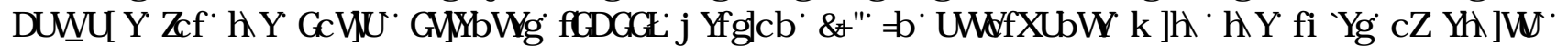

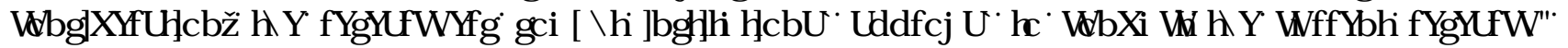

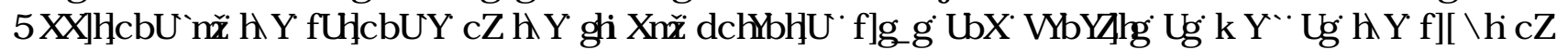

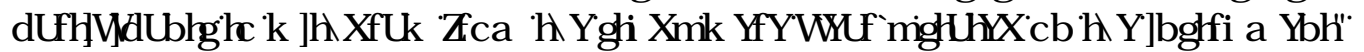

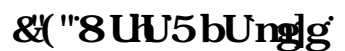

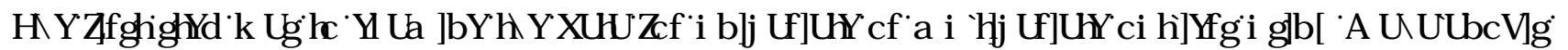

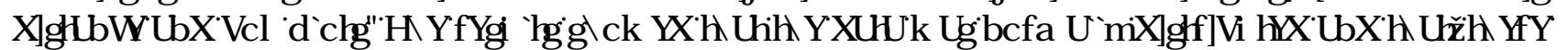

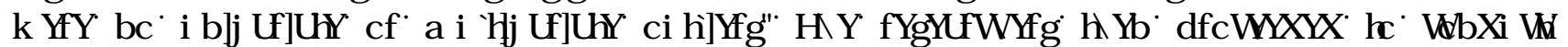

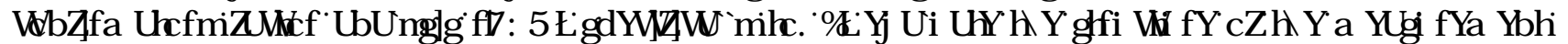

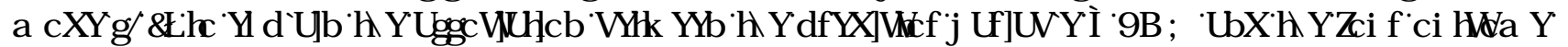

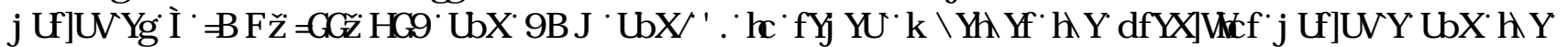

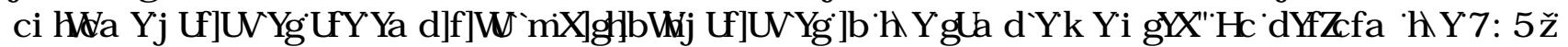

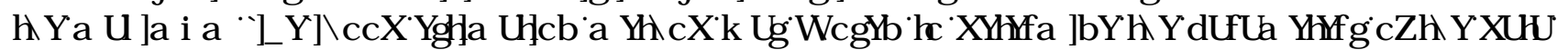

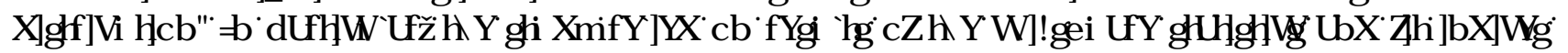

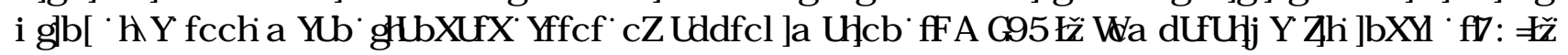

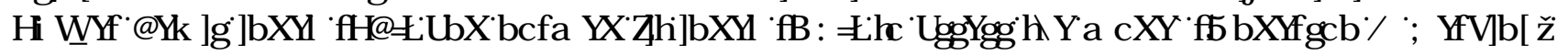

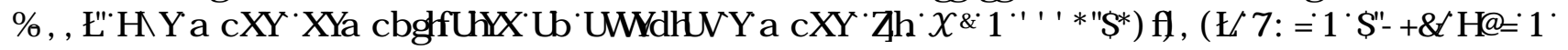

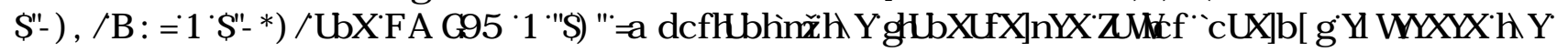

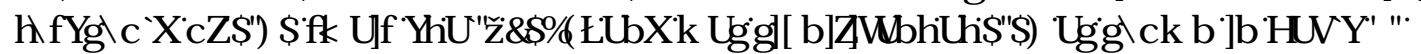

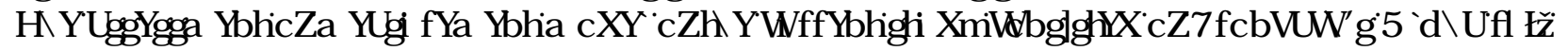

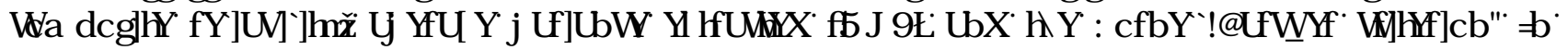

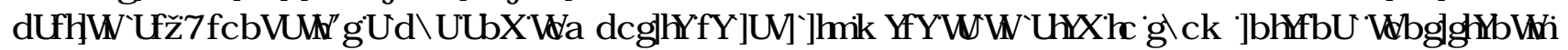

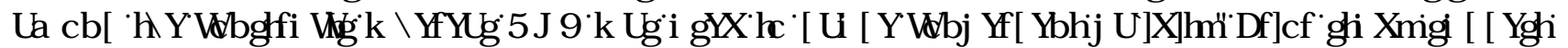

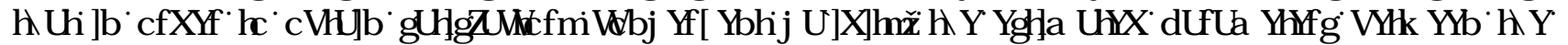

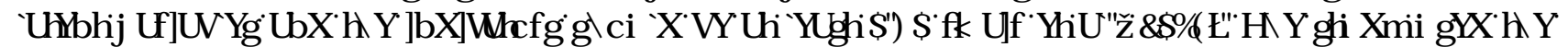

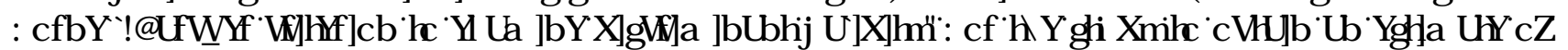

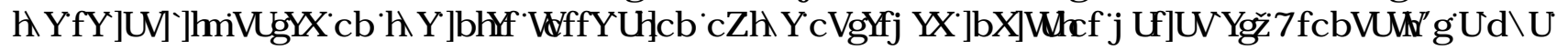

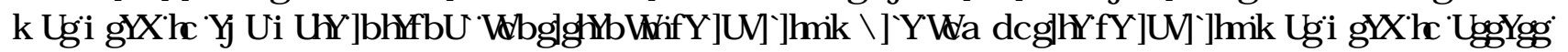

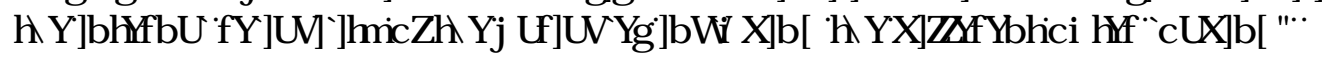

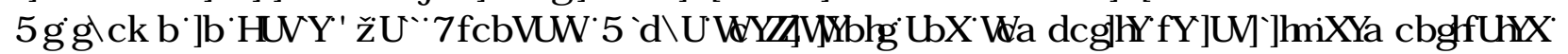

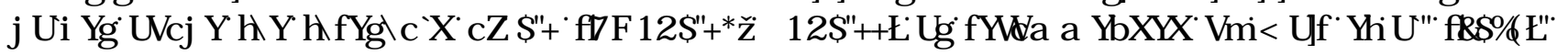

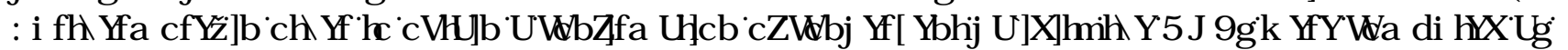

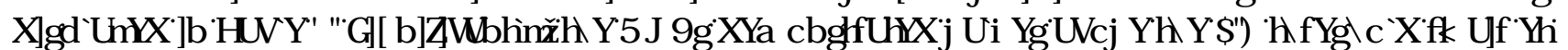

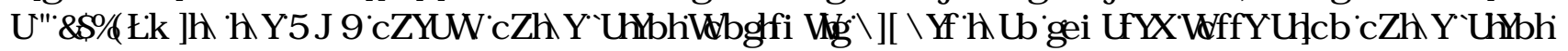

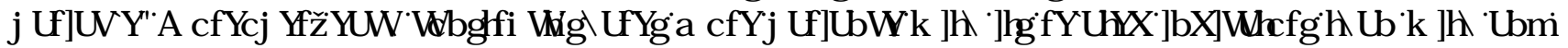

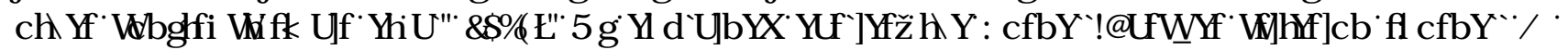

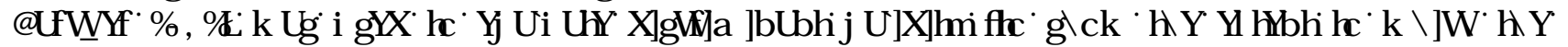

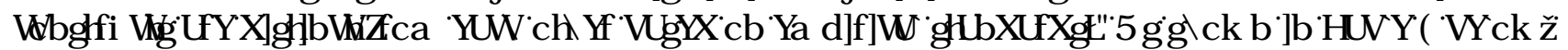

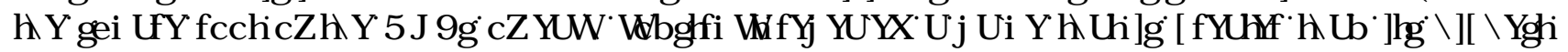

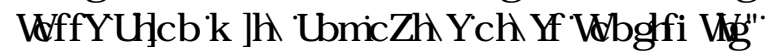

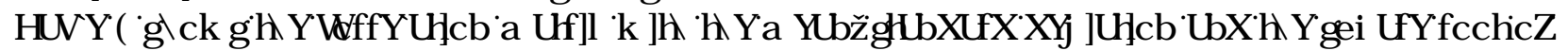

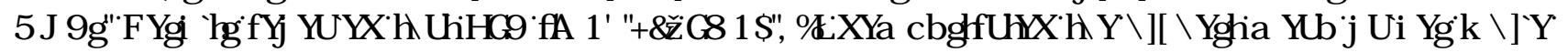

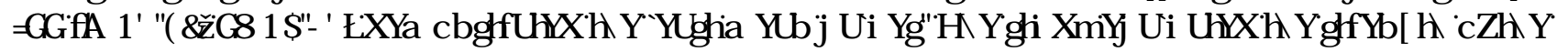

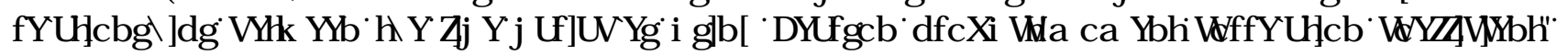

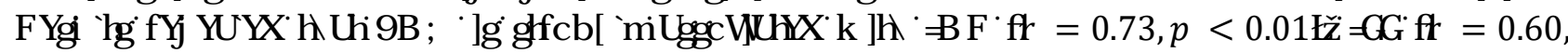

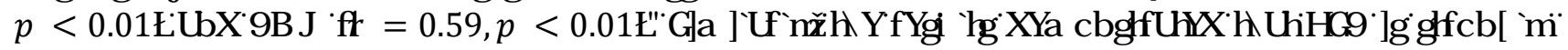
$\square$ 
7DEOHயI

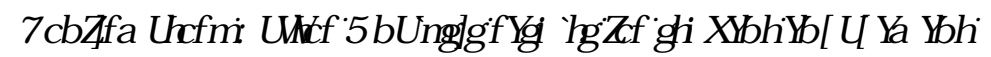

\begin{tabular}{|c|c|c|c|c|c|c|c|}
\hline 3DNAD & 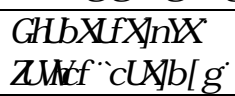 & $\begin{array}{l}\text { 6VDOGDG } \\
\text { HURUI }\end{array}$ & 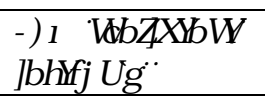 & $R^{2}$ YYOXHY & $\& \$ \square \mathbb{\square}$ & $\& 5 \square$ & $\$ 9(\square$ \\
\hline$(1 * / \square \mathbb{\|}(1 * \square$ & पा山ा & 口血四 & 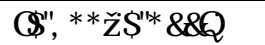 & 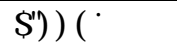 & & & \\
\hline 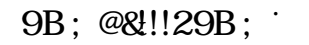 & वाण口 & वाण口 & Ð & वाला & & & \\
\hline 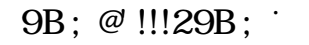 & 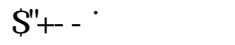 & वाण口 & 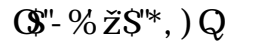 & पाण口 & & & \\
\hline ( $1 * / \square$ 盂 ( $1 * 0$ & एा⿵冂卄 & एس口冋 & 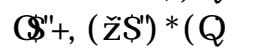 & 口㽞 & & & \\
\hline ( $1 * 3 \square$ 血 $(1 * \square$ & एण口冋 & एس口冋口 & 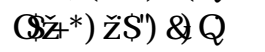 & 口㽞 & & & \\
\hline ( $1 * 3 \square \mathbf{m}$ ( $1 *$ * & वाण & वाण & 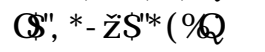 & 口㽞 & & & \\
\hline ( $1 * 3 \square$ ( $1 * 0$ & 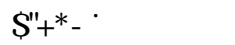 & 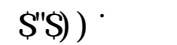 & 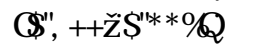 & 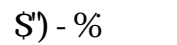 & & & \\
\hline ( $1 * 3 \square$ ( $1 *$ ( & 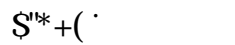 & पाण口卄 & 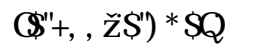 & एवाण & & & \\
\hline$\&\left(1 * \square\left[\begin{array}{ll}0 \\
(1\end{array}\right.\right.$ & एा⿵冂卄 & एس口冋 & 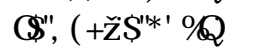 & 口㽞 & पाएण & एण口 & एण口冋 \\
\hline 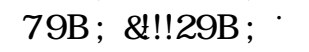 & एण口冋 & एس口冋口 & 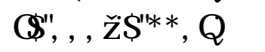 & 口㽞 & & & \\
\hline 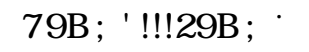 & एलाए & एسण口 & 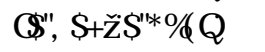 & 口㽞 & & & \\
\hline 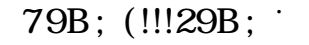 & 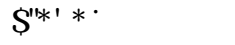 & वाण口 & 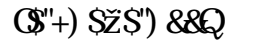 & वाण & & & \\
\hline $2(1 * \square[\mathbf{D}(1 * 0$ & 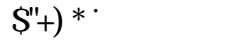 & वाण口 & 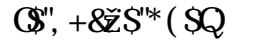 & वाण口 & & & \\
\hline 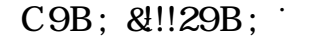 & एवाण & एயா & 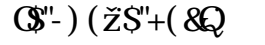 & एव口 & & & \\
\hline 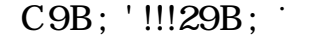 & एवाण & एய山 & 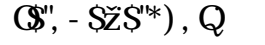 & 口四口 & & & \\
\hline 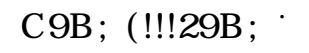 & पाणएण & एسण口 & 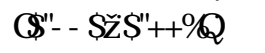 & एवण & & & \\
\hline , $165 \square\left[\begin{array}{l}1 \\
1\end{array}\right.$ & 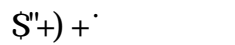 & 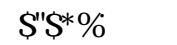 & 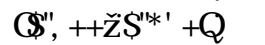 & 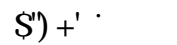 & & & \\
\hline , 1 65口内 150 & पा山ाण & एण口冋 & 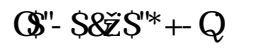 & 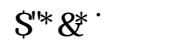 & & & \\
\hline 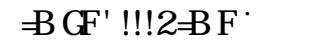 & पाण口ण & पाण口 & 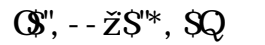 & एाण口 & पाणा & वाण & वाण口 \\
\hline 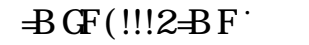 & 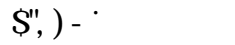 & वाण口 & Ð & वाण口 & & & \\
\hline 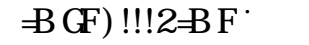 & 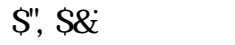 & वाण口 & 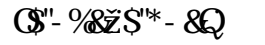 & पाण口 & & & \\
\hline 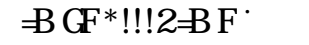 & वाण口 & वाण口 & 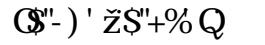 & वाण口 & & & \\
\hline , 1 66[0 & वाण口 & वाण口 & 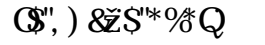 & वाण口 & & & \\
\hline , 1 66[0 & एवाण & एயா & 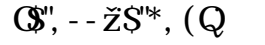 & एण口 & & & \\
\hline 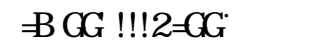 & 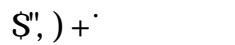 & 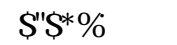 & 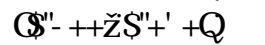 & 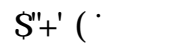 & 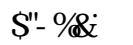 & एवाण & पाणा \\
\hline 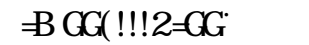 & एवाण & एवा & 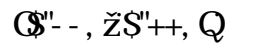 & एवा & & & \\
\hline 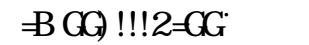 & पाणा & वाण口 & 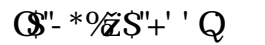 & एाएण & & & \\
\hline 7( 6( वाण 76) & एणाएण & 口媳 & 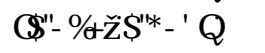 & 口ण口冋口 & & & \\
\hline 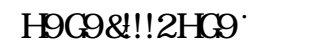 & पाणाण & एाण口 & 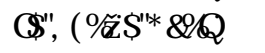 & 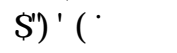 & & & \\
\hline 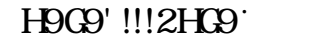 & वाण口 & वाण口 & 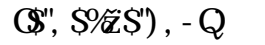 & वाण口 & एवाण & वाण & वाण口 \\
\hline 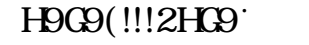 & वाण口 & वाण口 & 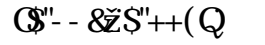 & वाण口 & & & \\
\hline 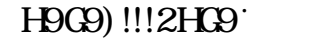 & एवाण & एயण口 & 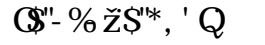 & एण口 & & & \\
\hline 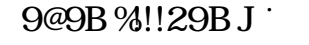 & एलाए & एயா & 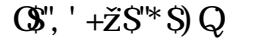 & 口四口 & & & \\
\hline ( / ( 1 ए内 ( 190 & पाणाण & एाण口 & 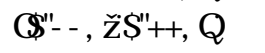 & 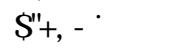 & एणाए & पण口卄 & पाण口 \\
\hline 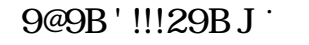 & वाण & 口血四 & 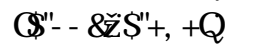 & वाण & & & \\
\hline 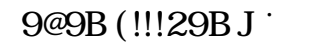 & 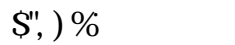 & एवाण & 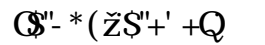 & एाएव & 四 & 四 & 四 \\
\hline 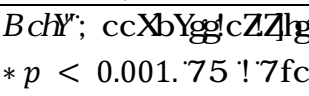 & 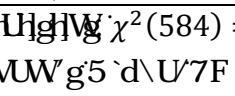 & $=$ & 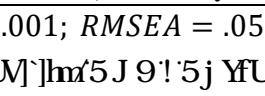 & $\begin{array}{l}C F I= \\
-9010\end{array}$ & $T L I$ & & \\
\hline \multicolumn{8}{|l|}{ 7DEOM! } \\
\hline \multicolumn{8}{|c|}{ 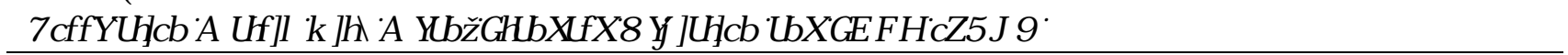 } \\
\hline $0(\$ 10$ & $67^{\prime}(9 \square$ & 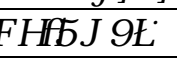 & $(1 * \square$ & ,66[ & & $5(\square$ & $(19 \square$ \\
\hline 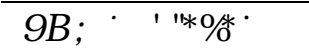 & 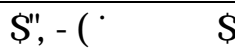 & $\Pi$ & 口盂四 & & & & \\
\hline ,15口 वणD & 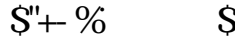 & 田 & एण口冋 & 口 & & & \\
\hline ,66口 पण口 & एس⿵冂卄 & 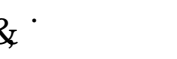 & 畐口四 & ए11 & & & \\
\hline 76( & एण口冋 & Ш口 & 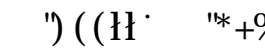 & Ш口 & ] & एण & \\
\hline ( $19 \square$ 口णए & एण口冋 & & एण口冋 & एШ & D. & एण & पएण \\
\hline
\end{tabular}

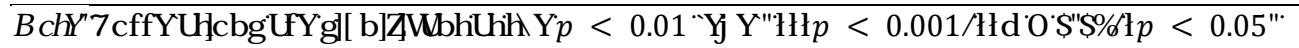




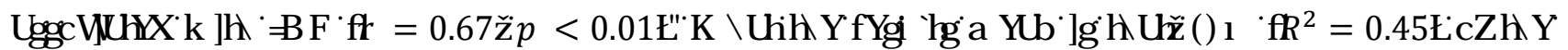

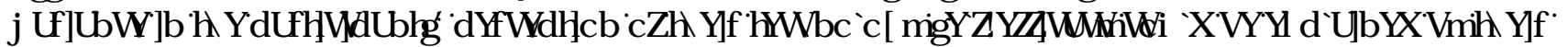

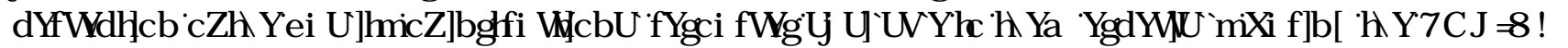

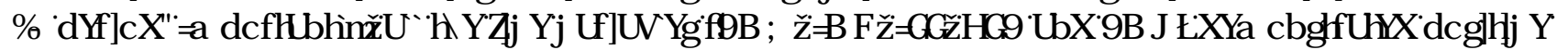

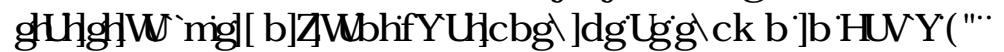

\section{]}

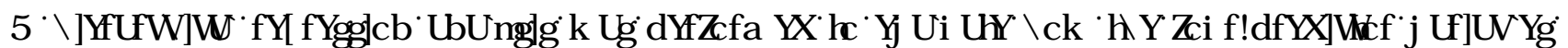

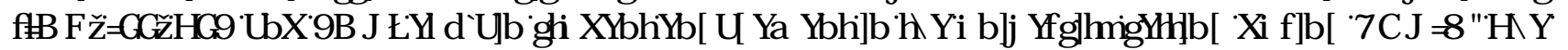

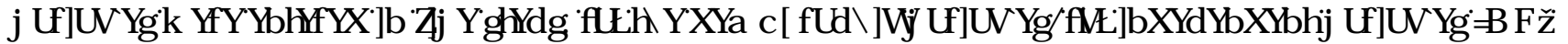
,66س76( [DQG 1 9

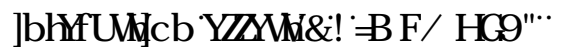

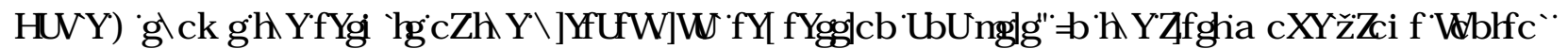

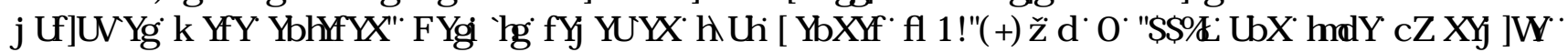

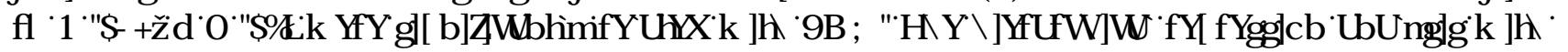

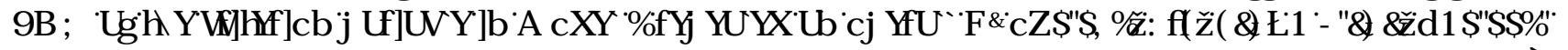

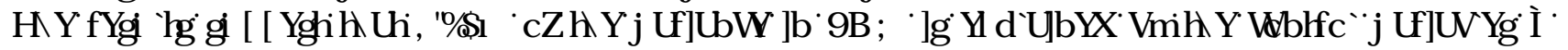

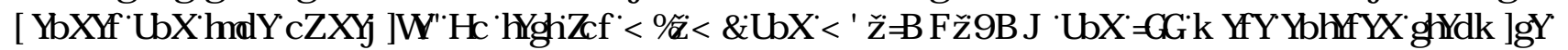

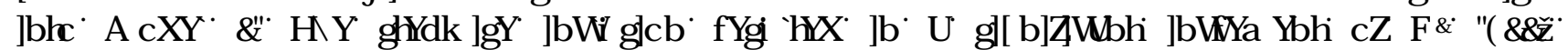

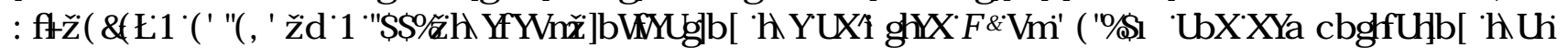

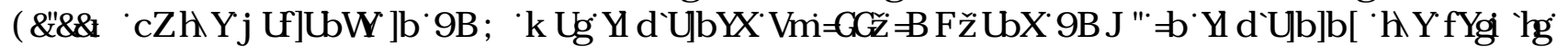
IXUKसU

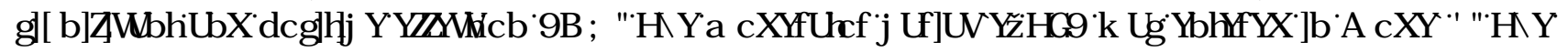

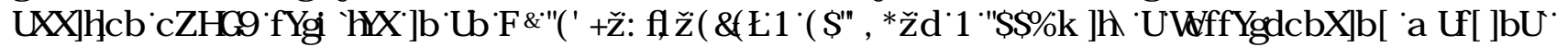

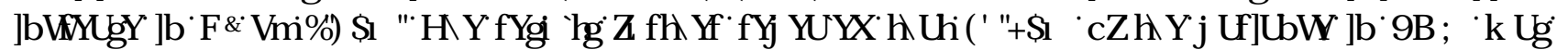

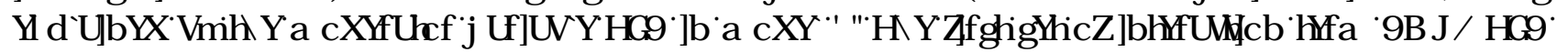

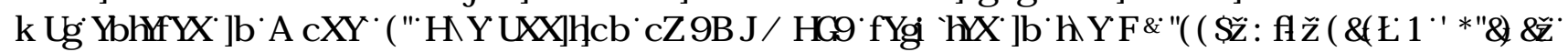

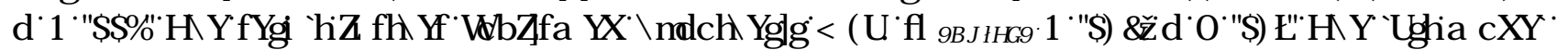

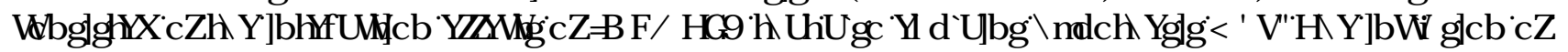

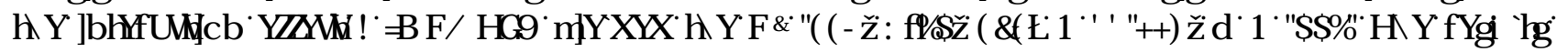

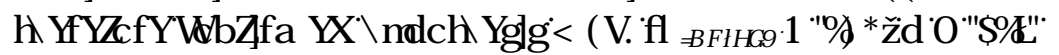

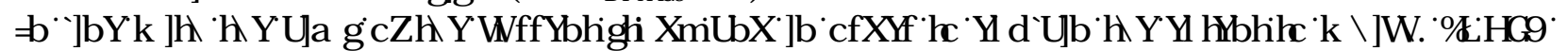

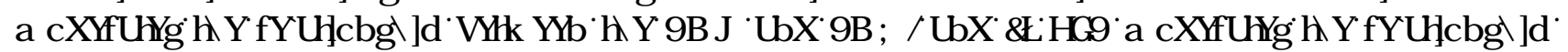

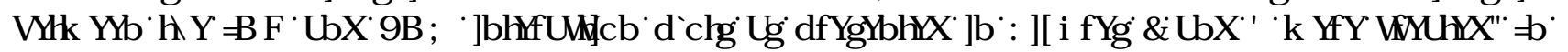

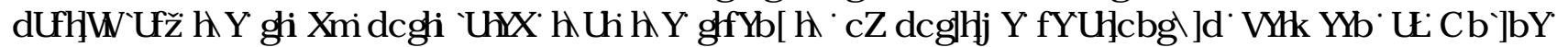

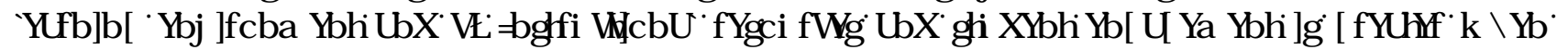

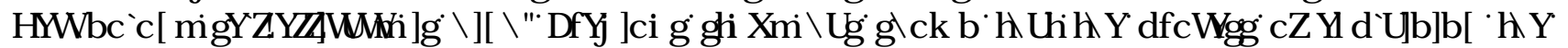

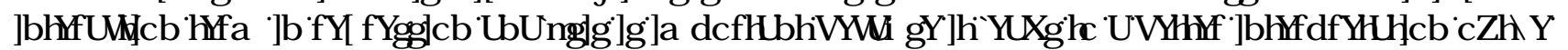

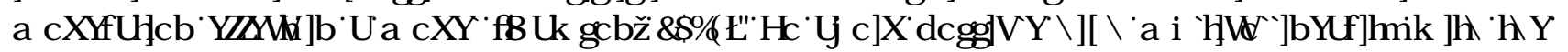

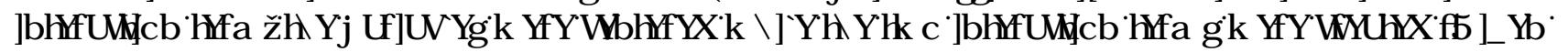

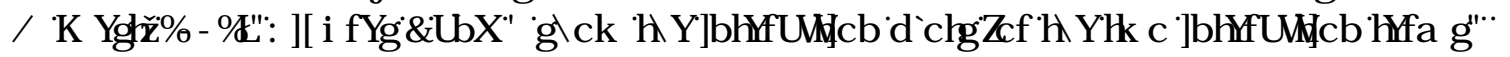




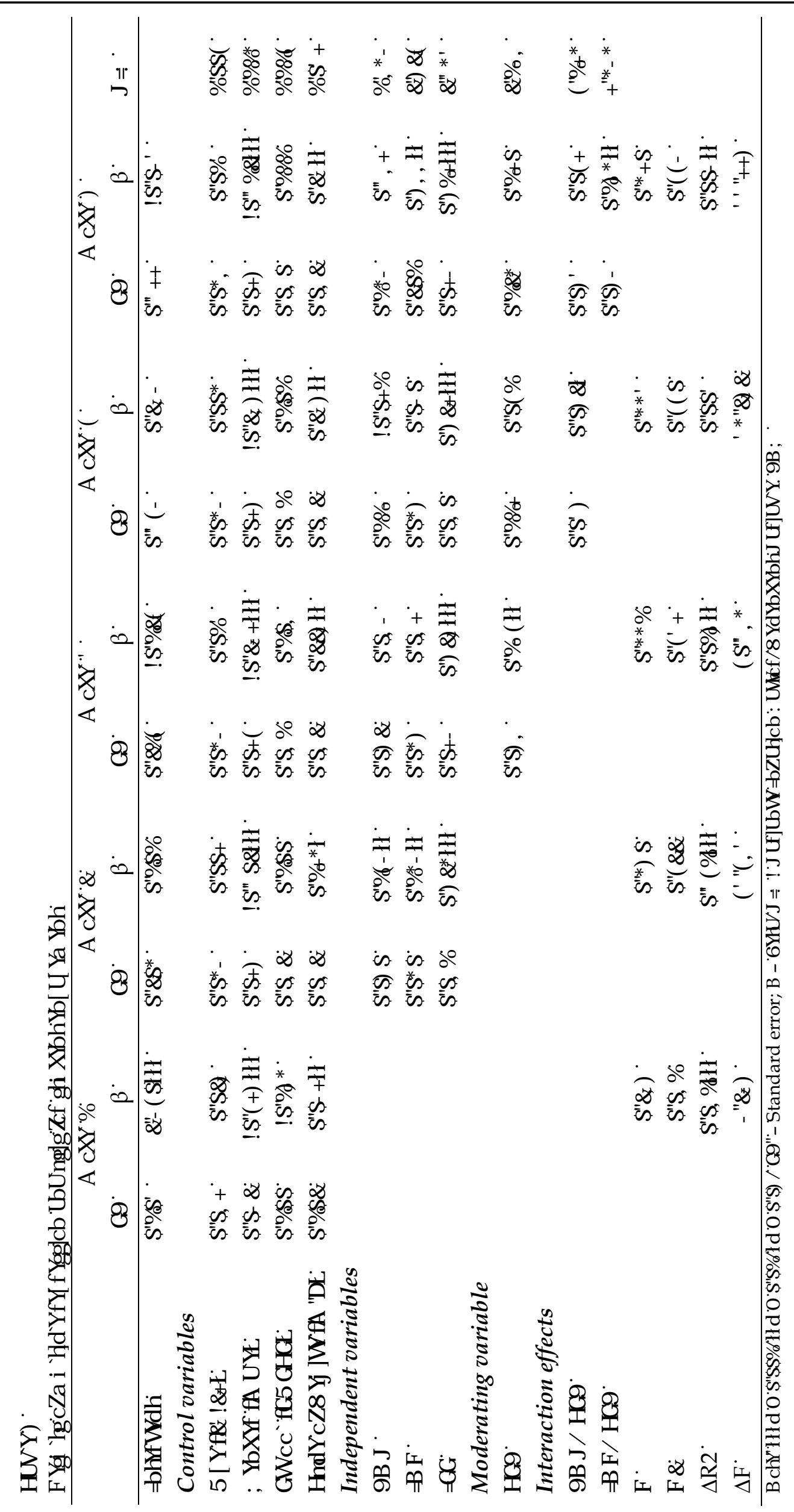


) \ XUH四

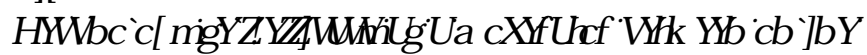

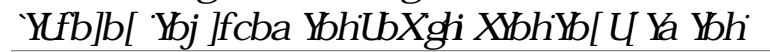

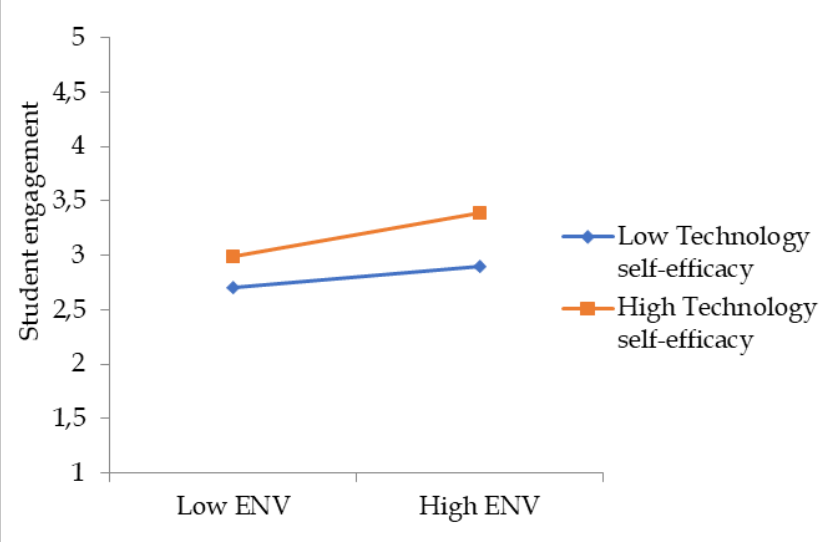

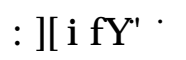

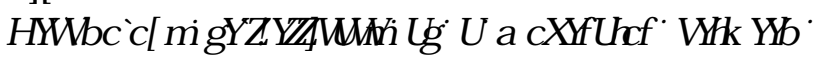

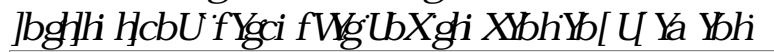

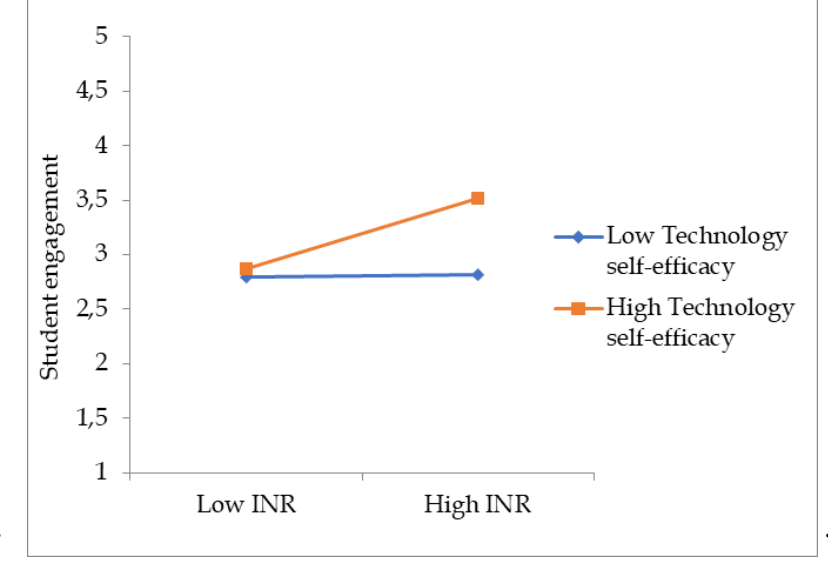

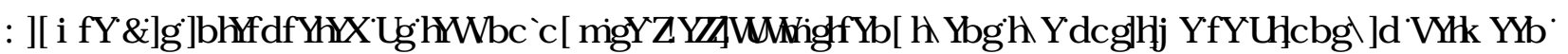

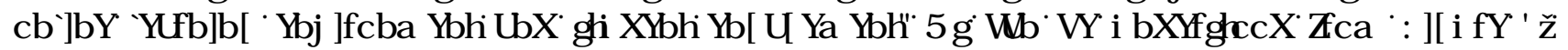

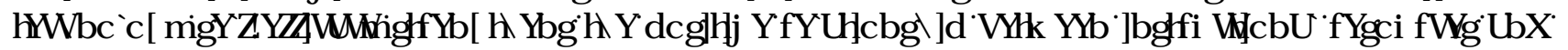
WXGHQNHQ D HP HQVM

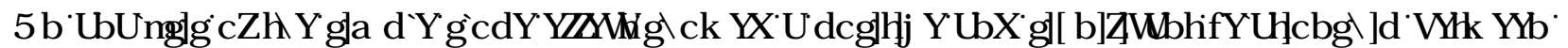
7HFQRQR \

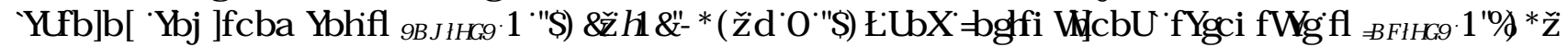
W

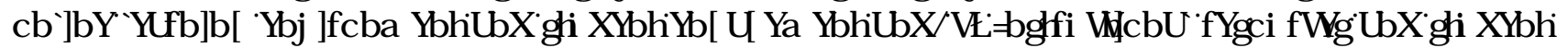

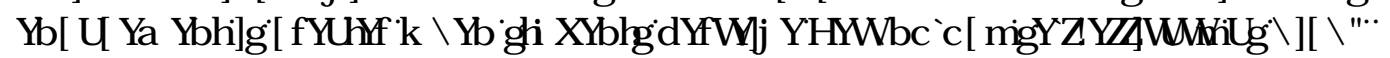

\section{口II" LPXWRQ}

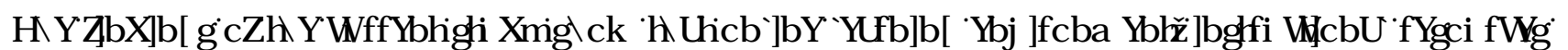

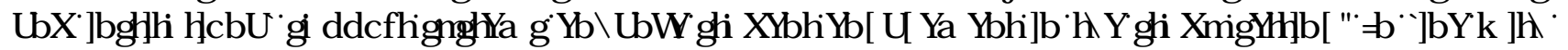

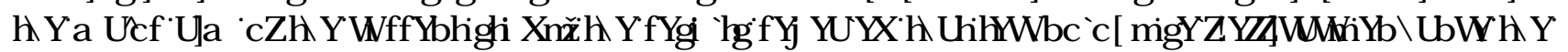

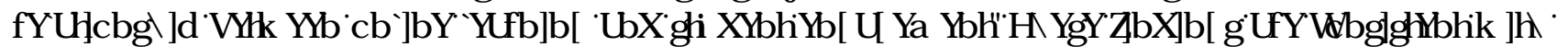

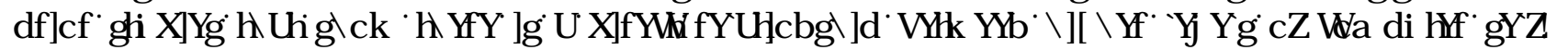

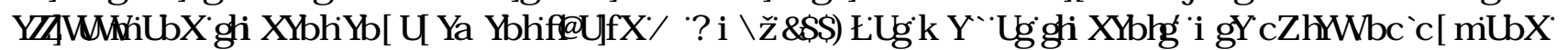

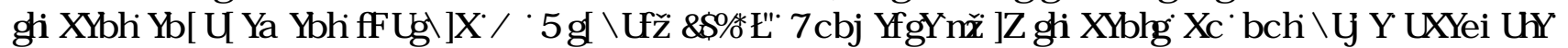

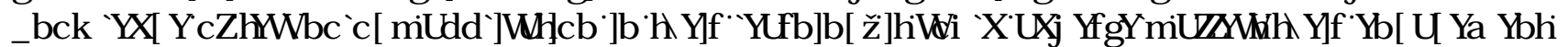

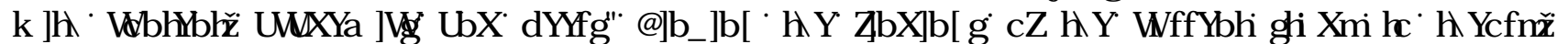

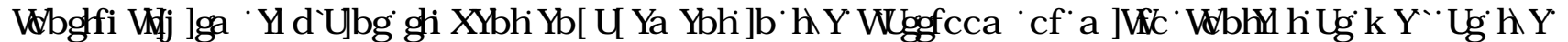

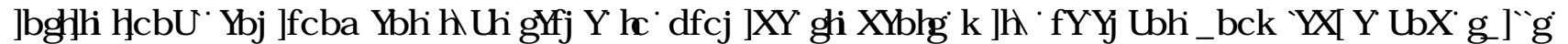

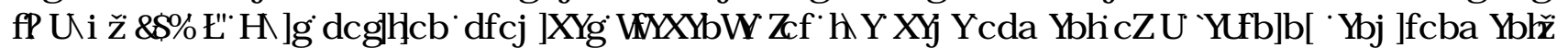

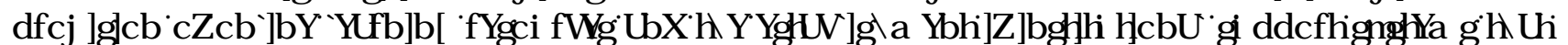
HQKDOFHRQOQHIADFKL IDQGTODQL

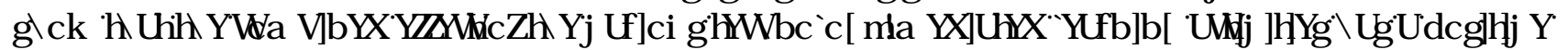

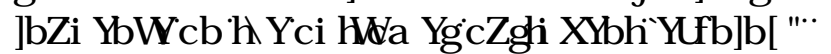

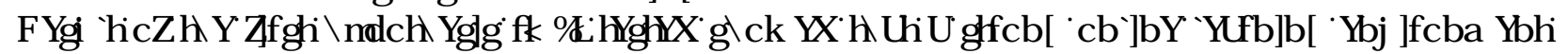

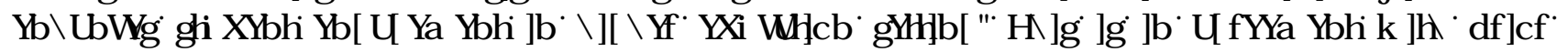

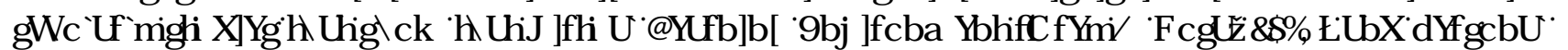

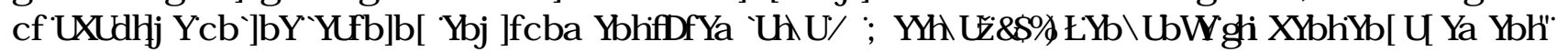

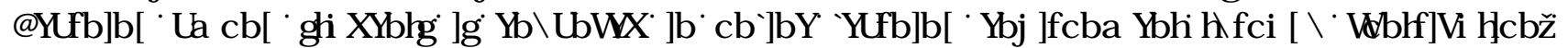
SDUFLSDURQDOGFRKHMRQDP RQ IKXGHQW

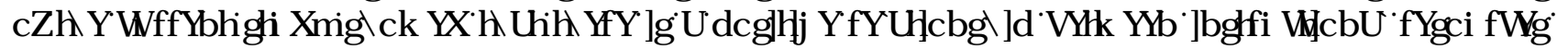




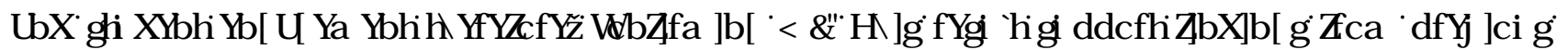

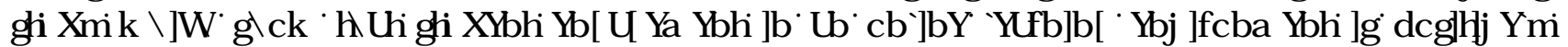

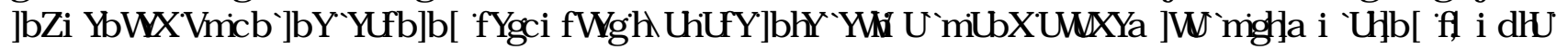
पBBDGH

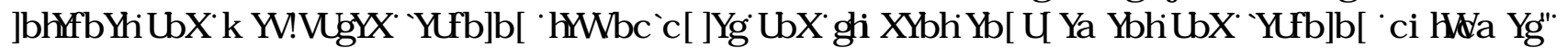

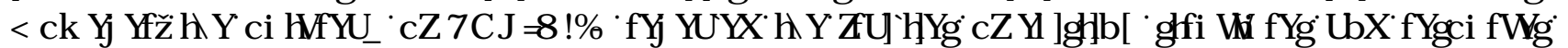

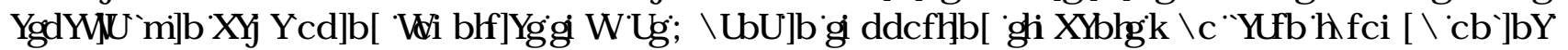

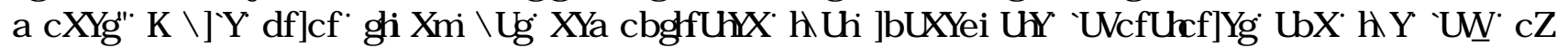

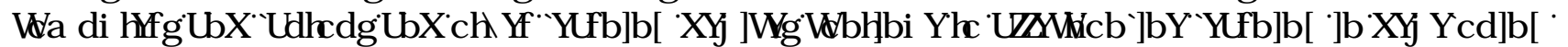

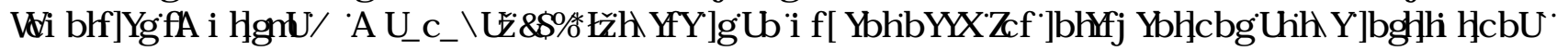

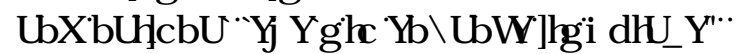

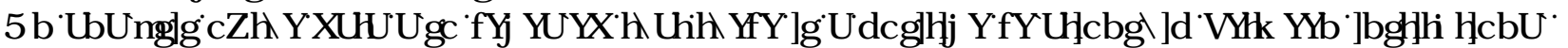

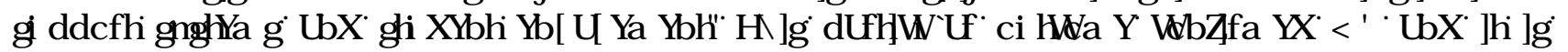

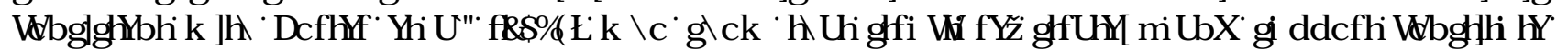

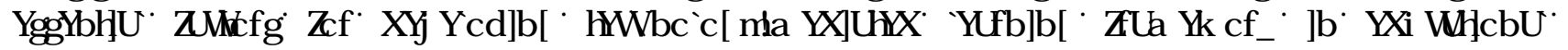

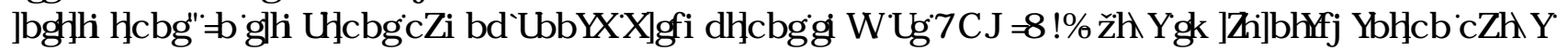

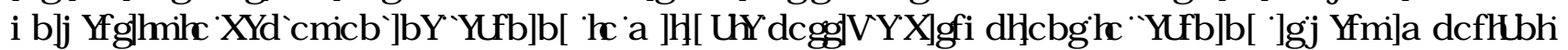

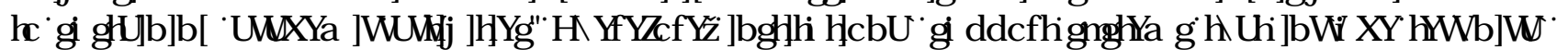

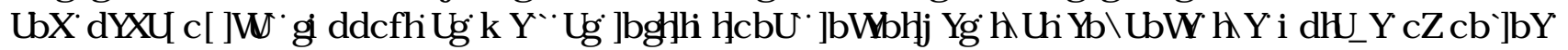

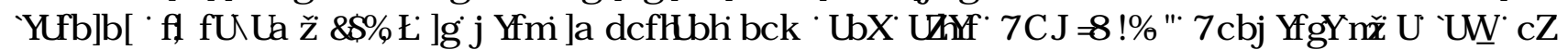

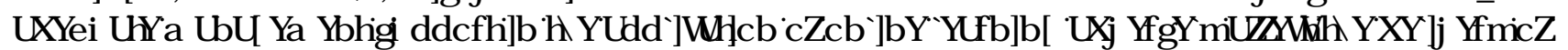

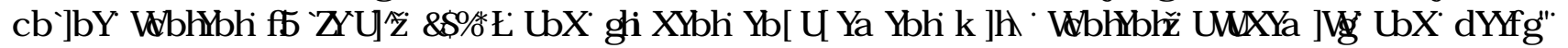

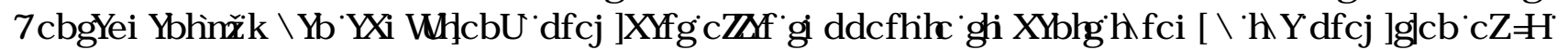

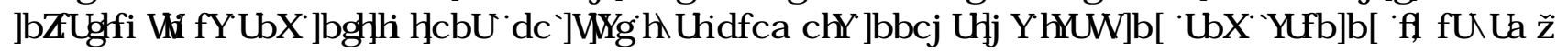

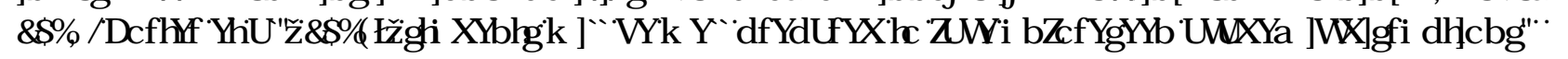

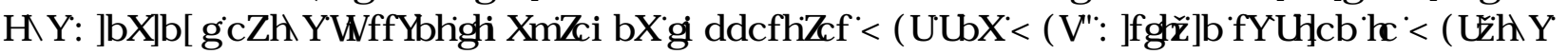

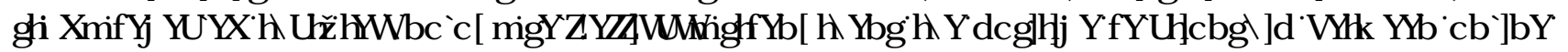

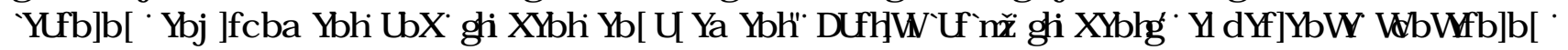

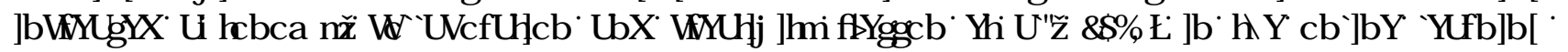

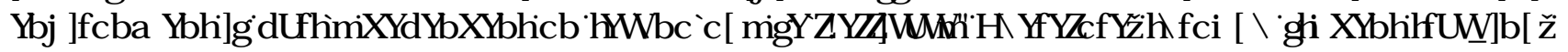

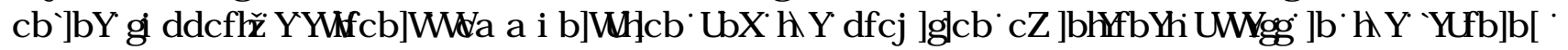

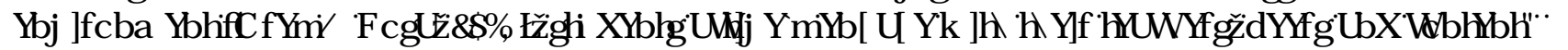

6HFRQG

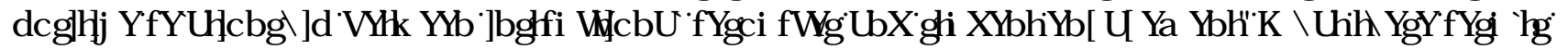

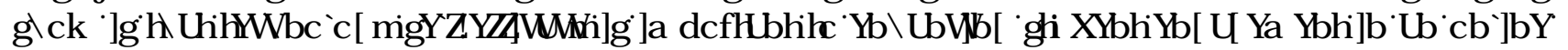

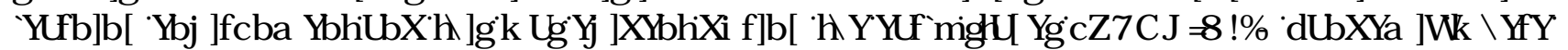

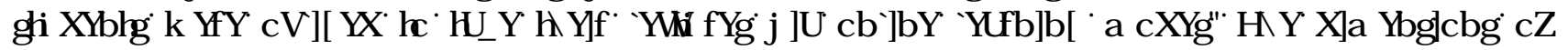

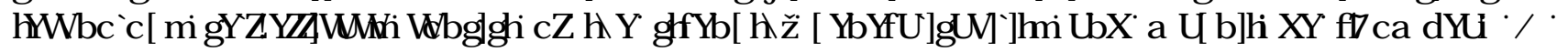

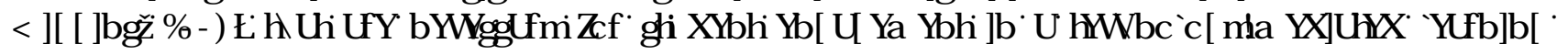

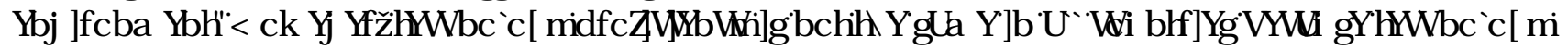

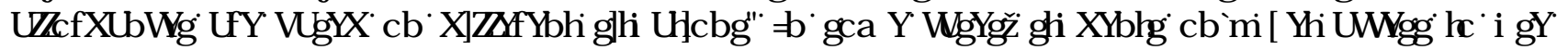

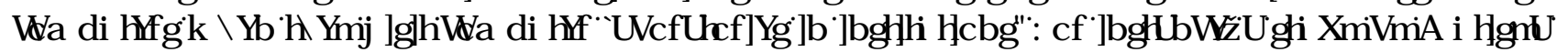

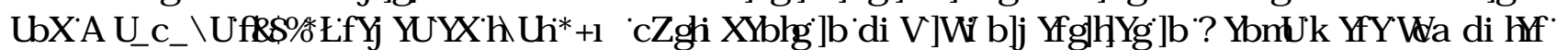

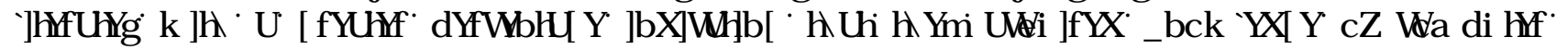

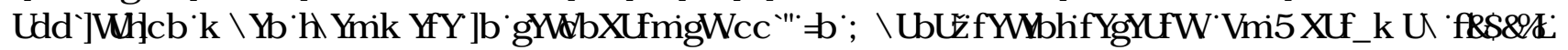

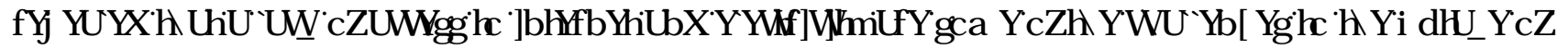
RQOQHEDQR II

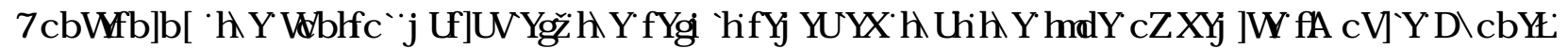

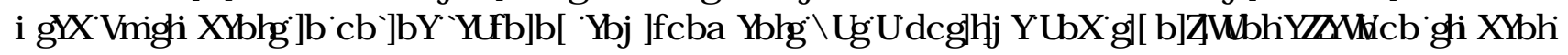

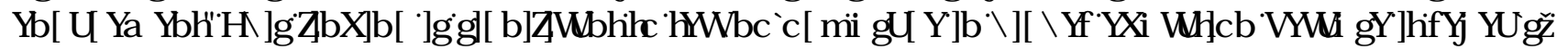

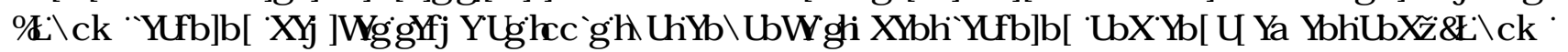




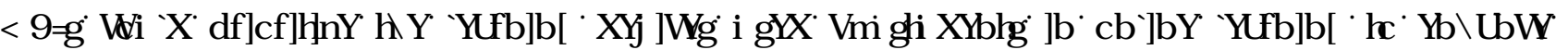

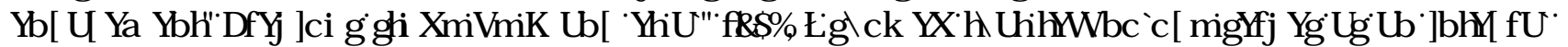

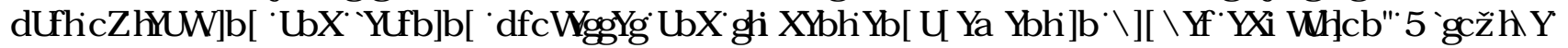

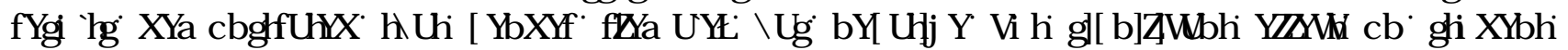

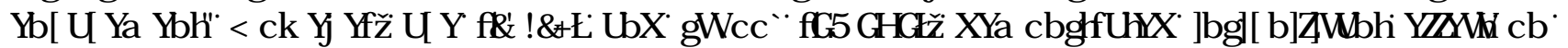
WXGHQWHD D HP HQWWII

\section{IIIIII GXFDRQDQP SCFDRQV]}

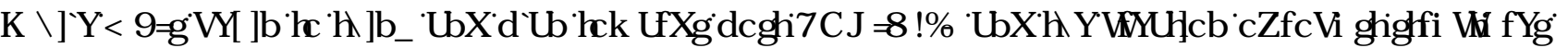

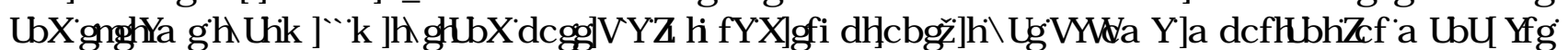

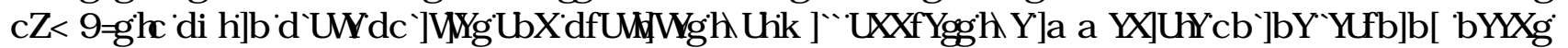
R $\square$ WXGHQW]DQG KDGZ DH

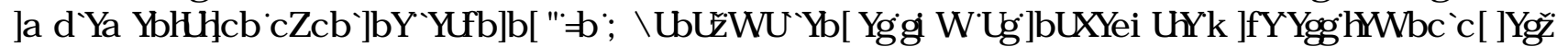

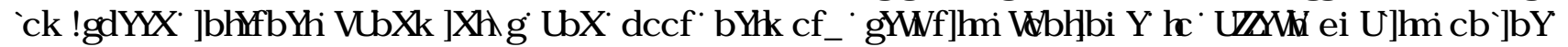

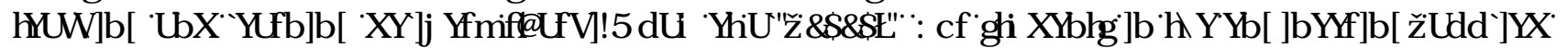

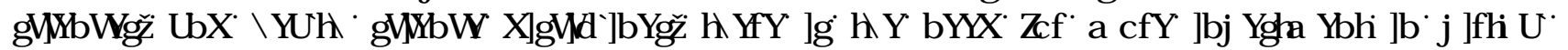

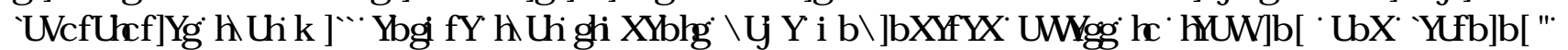

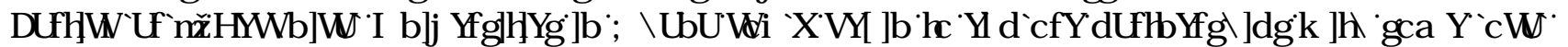

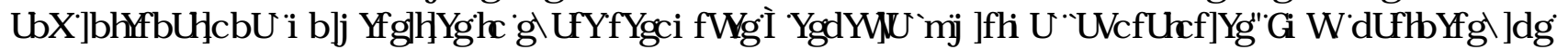

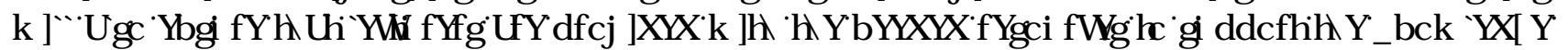

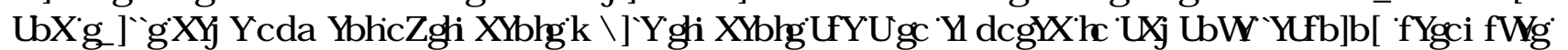

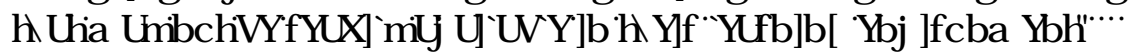

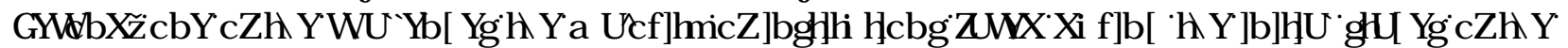

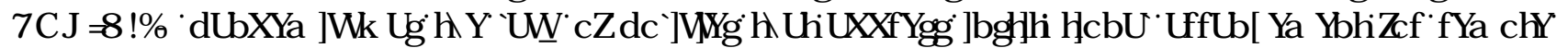

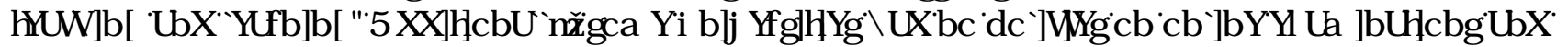

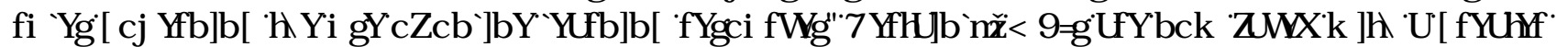

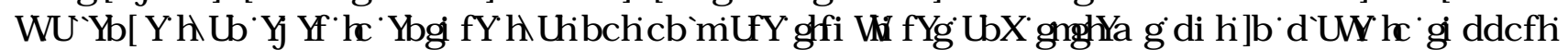

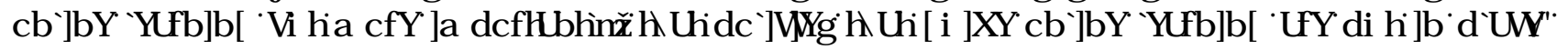

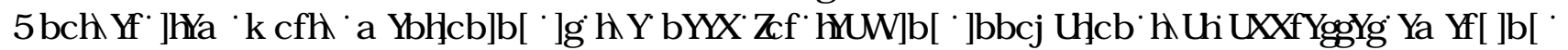

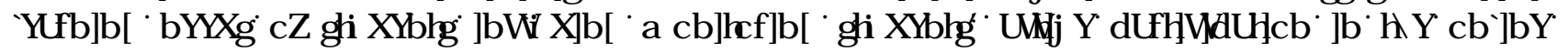

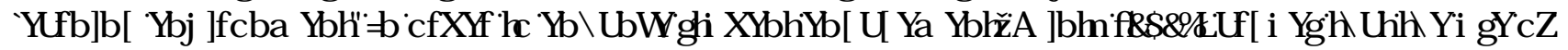

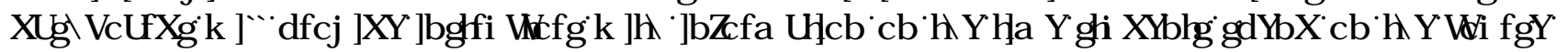

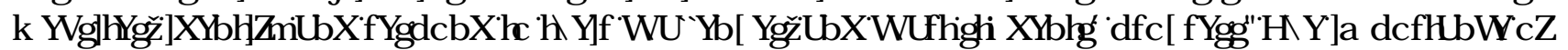

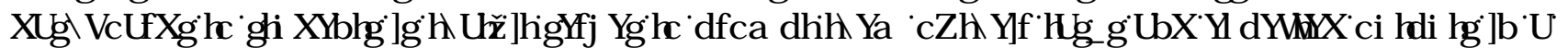

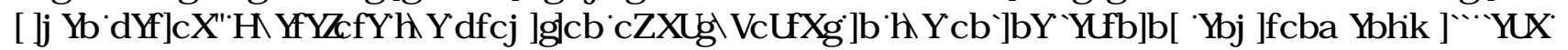

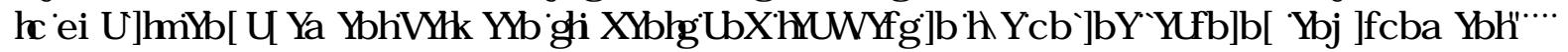

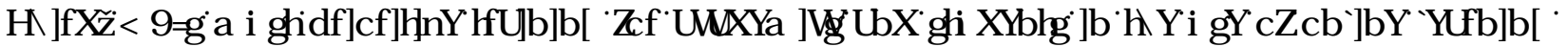

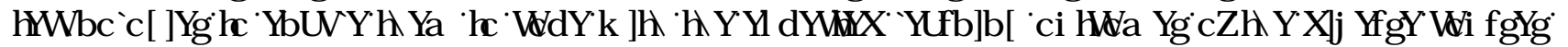

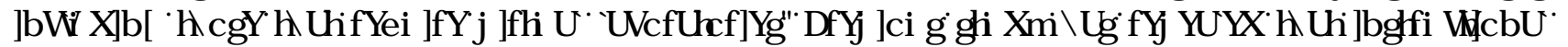

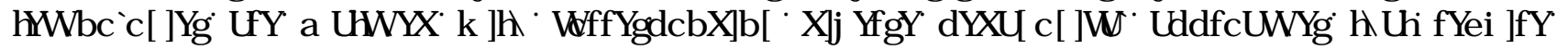

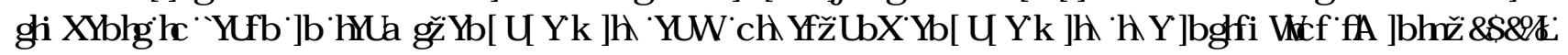

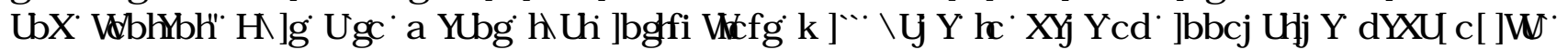

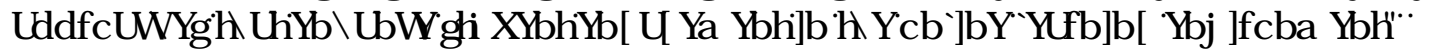

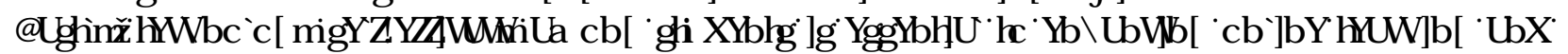

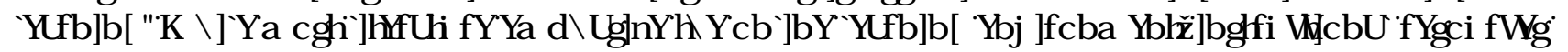

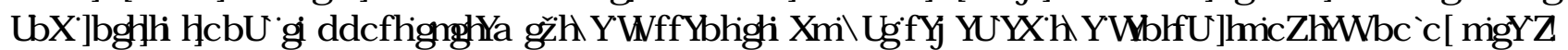

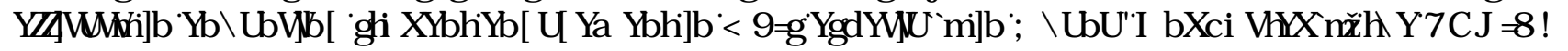

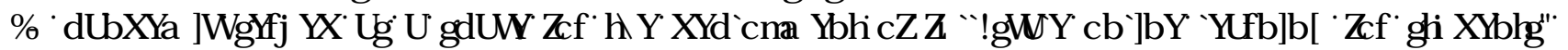

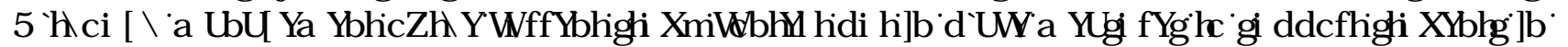

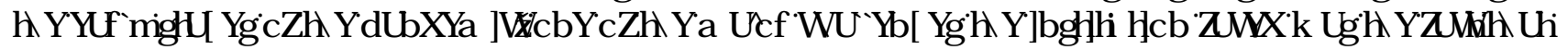




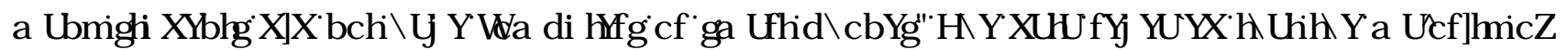

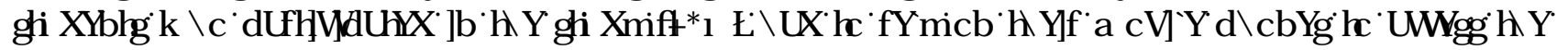

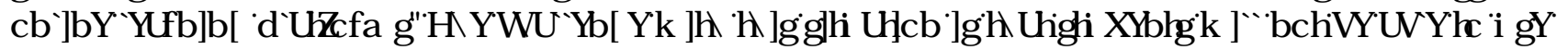

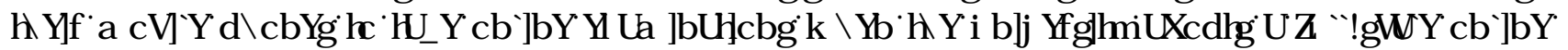

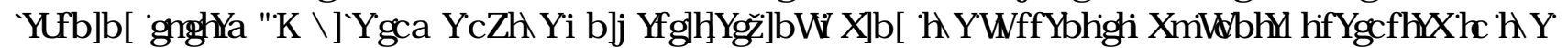

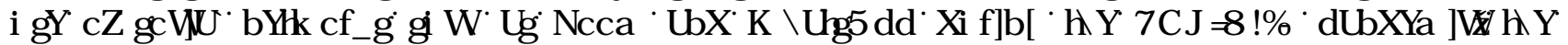

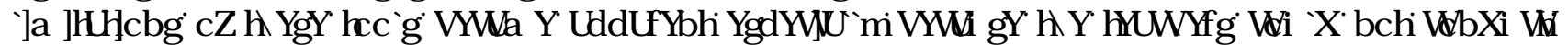

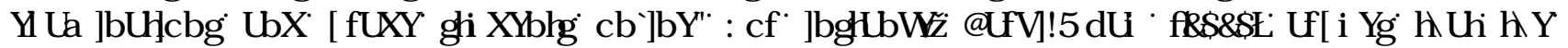

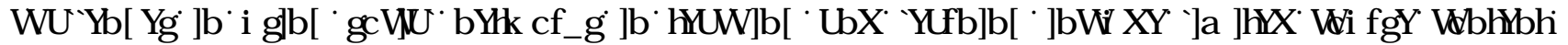

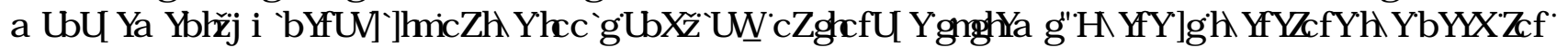

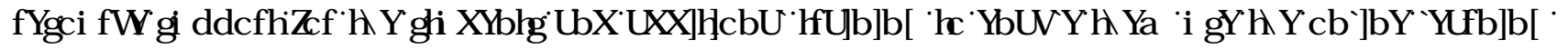
P RGHRI GHOYHY U]

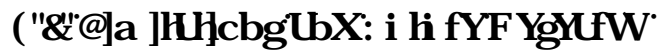

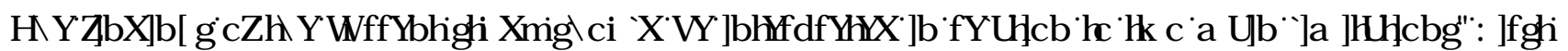

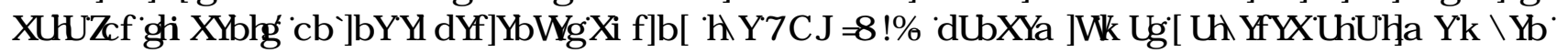

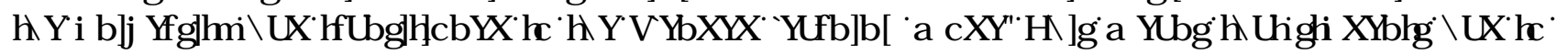

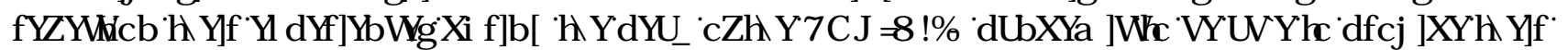

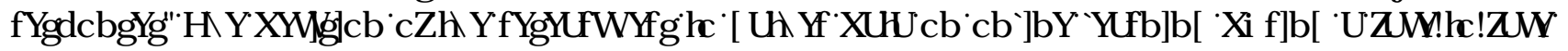

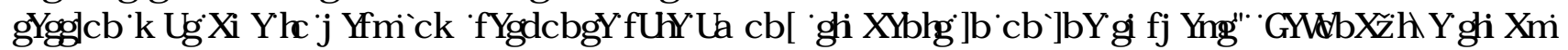

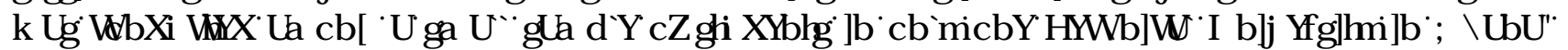

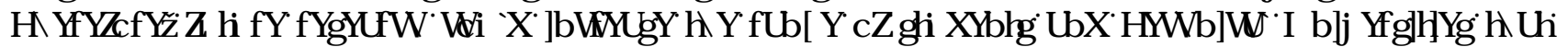

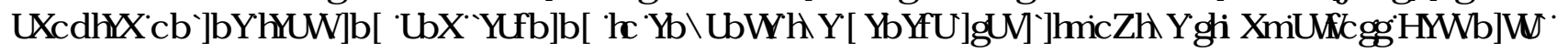

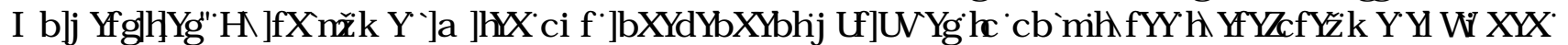

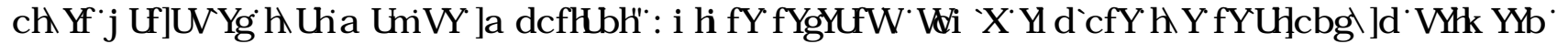

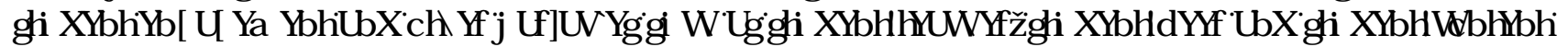
LQMAFURQII

\section{TISRQFONRQM}

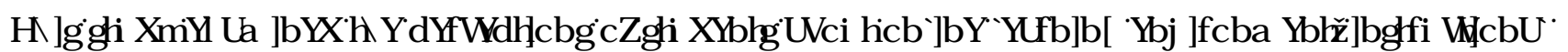

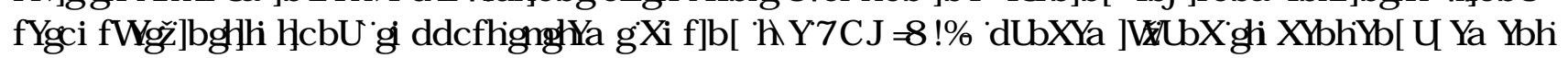

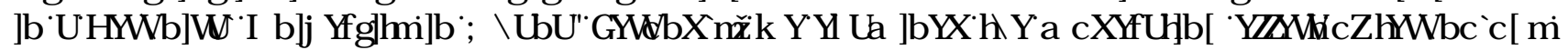

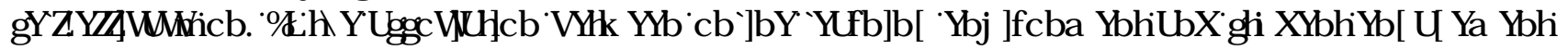

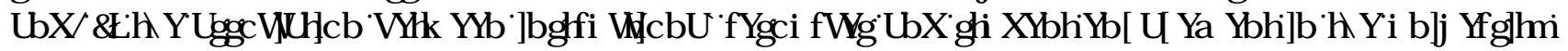
GXUQ $\square \& 2$ 9,'

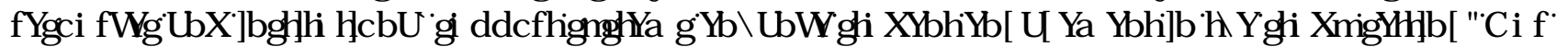

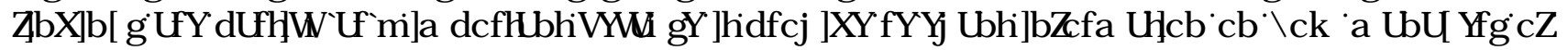

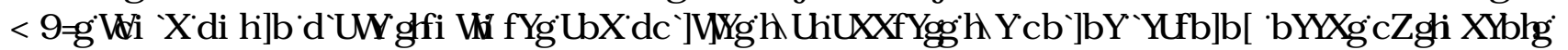

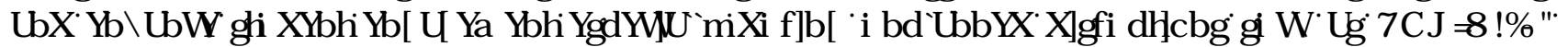

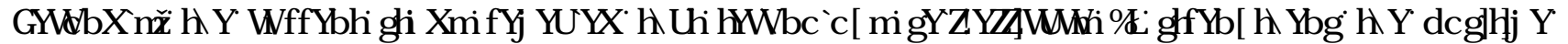

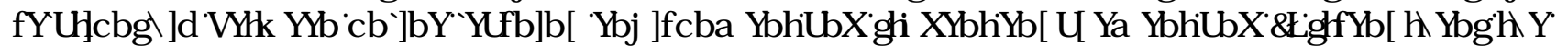

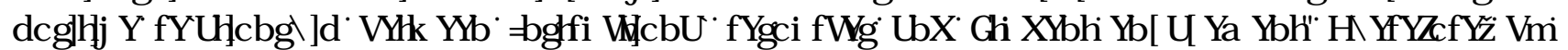

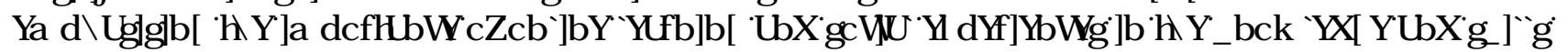

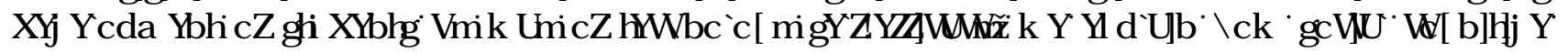

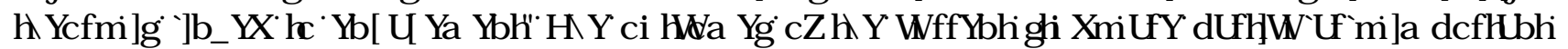

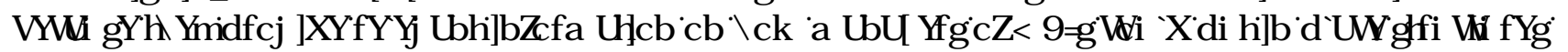

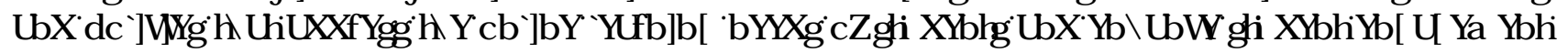

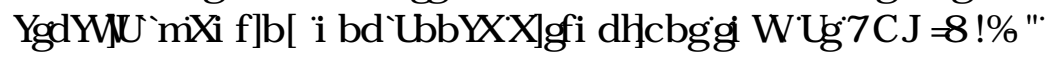




\section{HHWQPM}

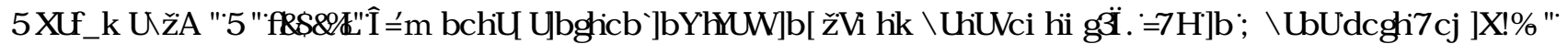

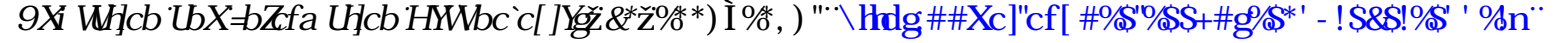

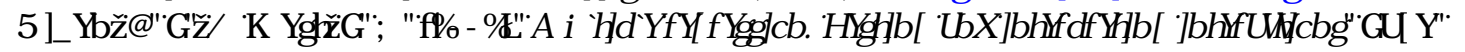

\$ OHOMMP/

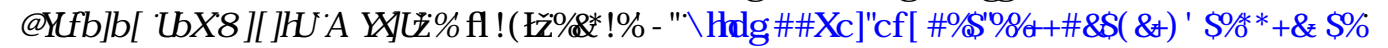

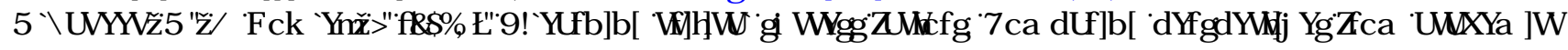

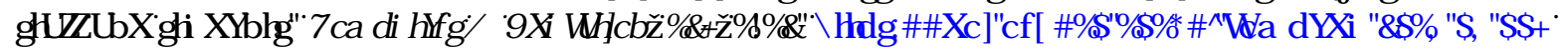

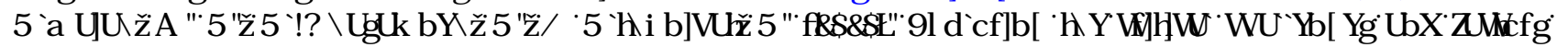

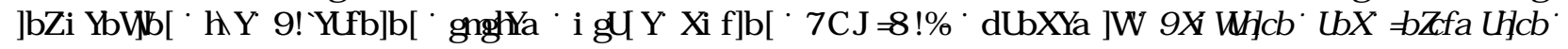

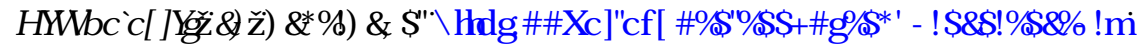

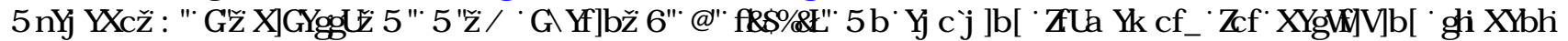

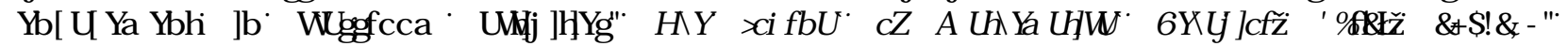

KWSVMDGRLRY

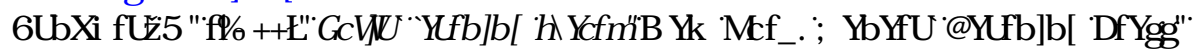

\%QQDQT]

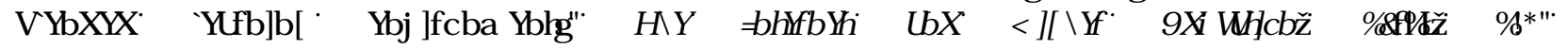
KWSVMDGRLRY

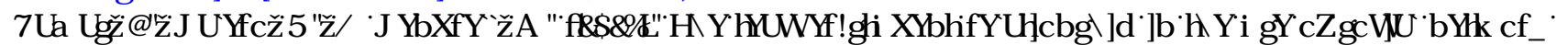

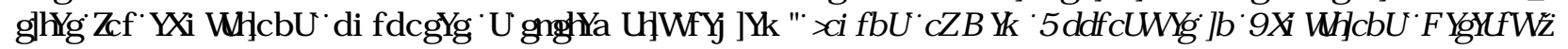

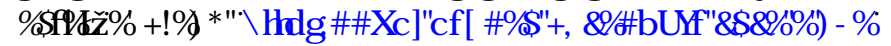

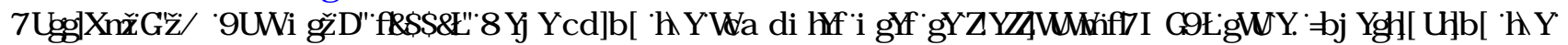

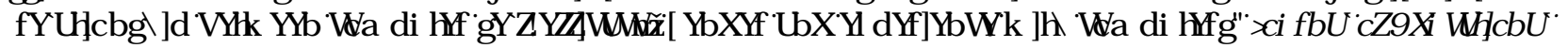

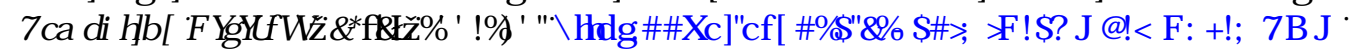

\&KHQ

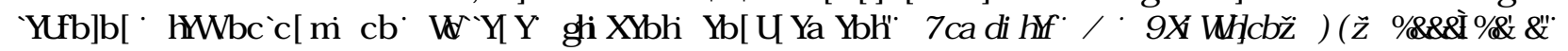

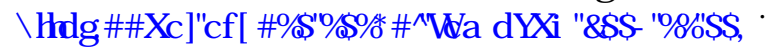

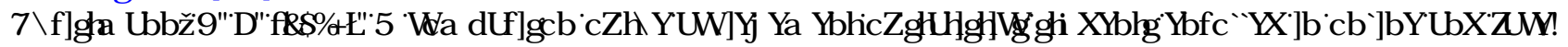

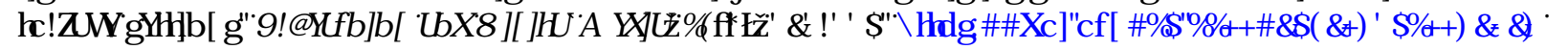

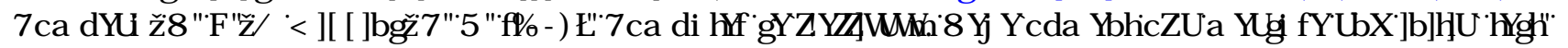

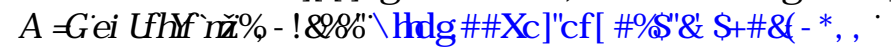

\&RWOH [I]

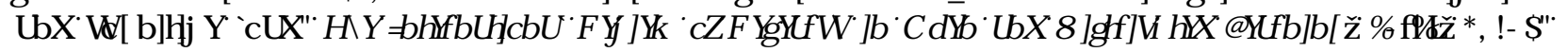

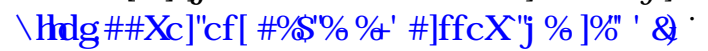

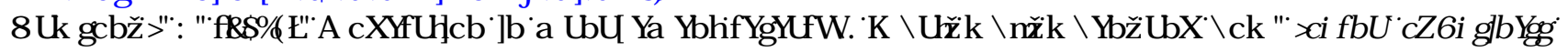

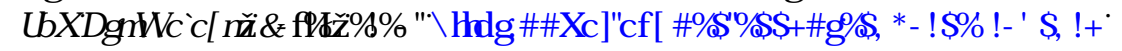

' KDZ DQ

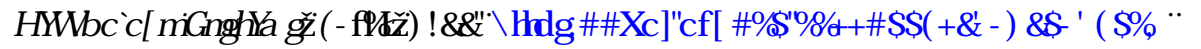

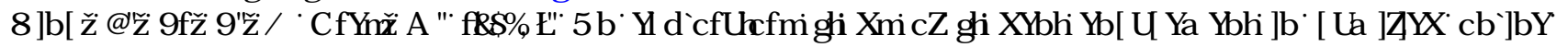

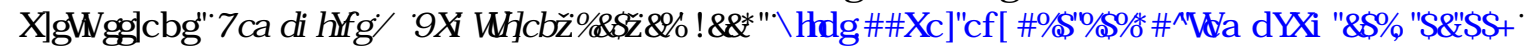

) Hy XVRQW5

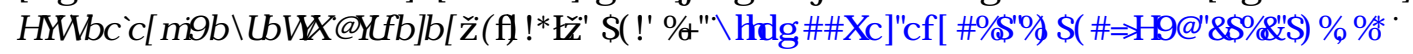

) RLQHQ⿻ा\&

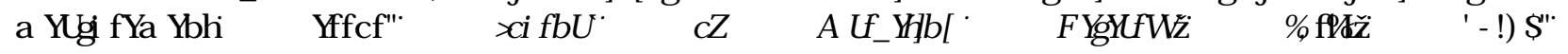

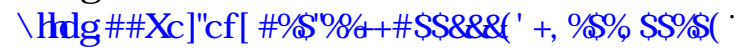

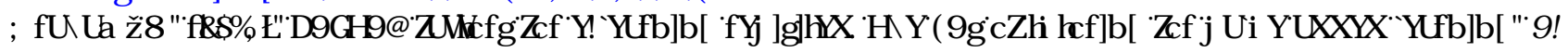

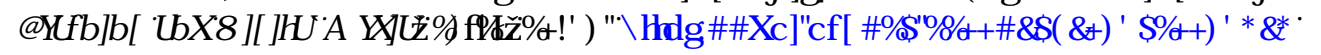

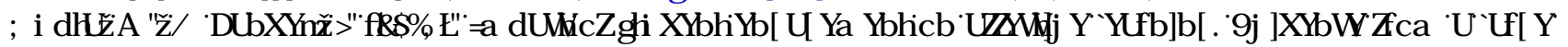

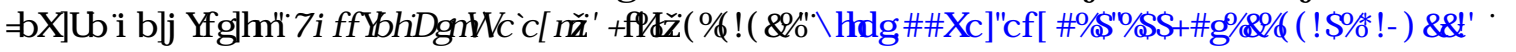

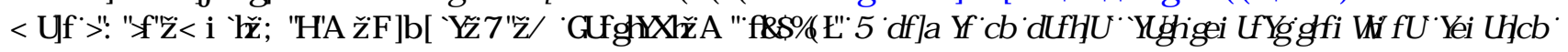

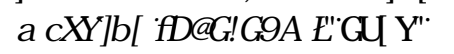

+ HQUH

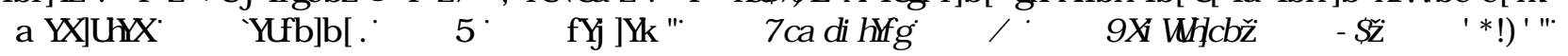

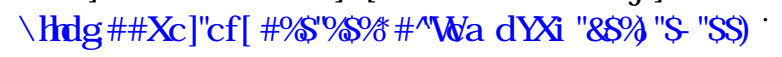


+RZ DGTा6س

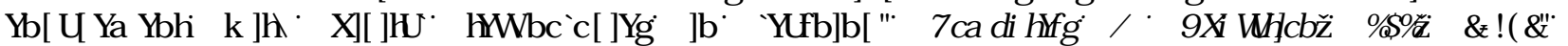
KWBVIDGRLRY

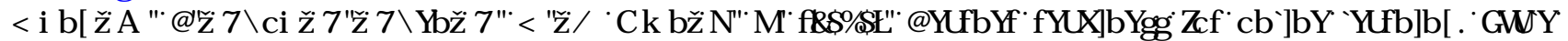

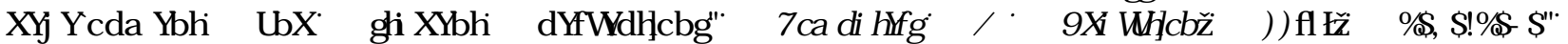

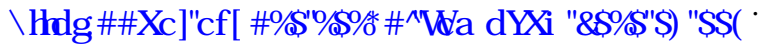

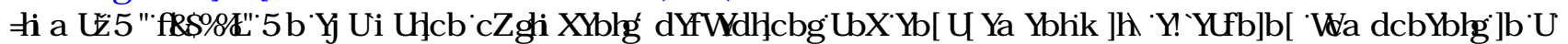

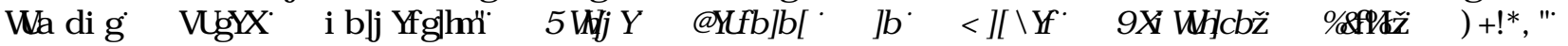
KWSVIDGRLRU

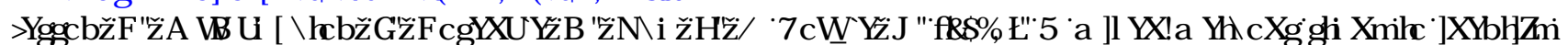

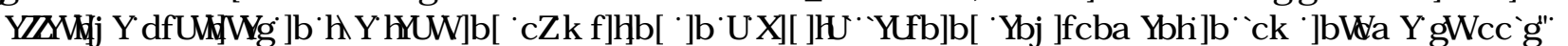

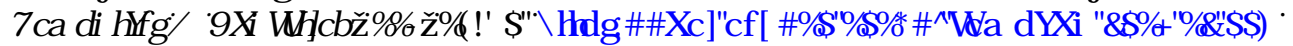

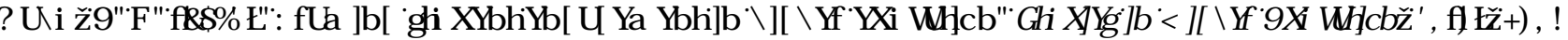

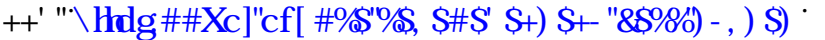

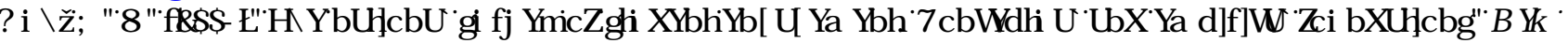

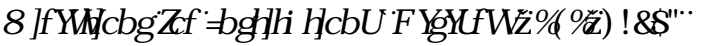

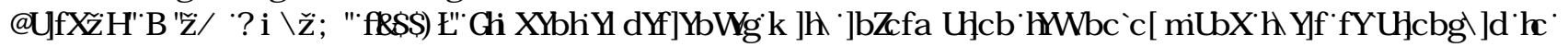

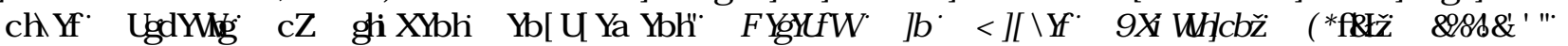

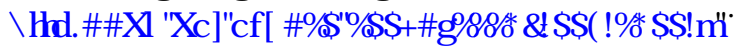

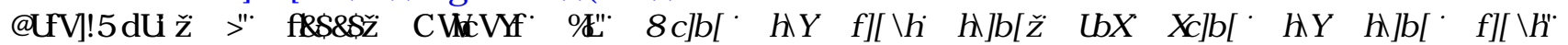

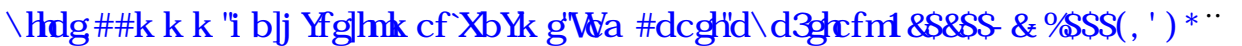

/ DEL \$ SDX

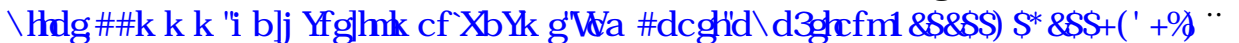

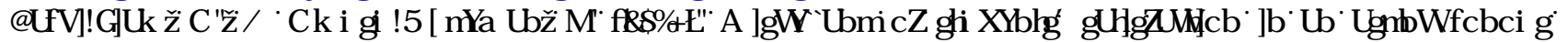

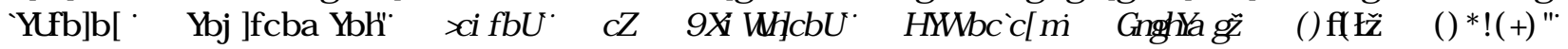

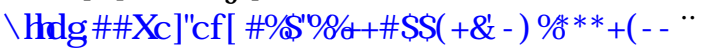

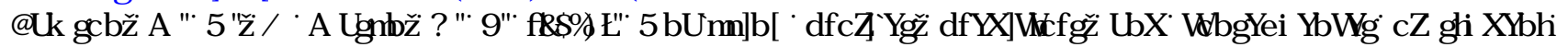

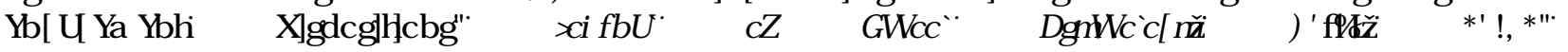

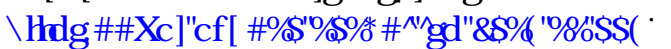

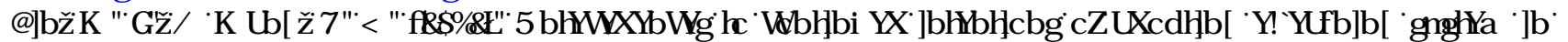

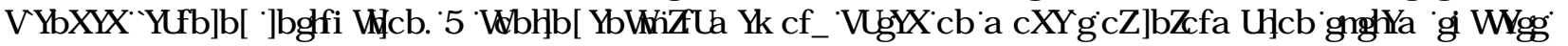

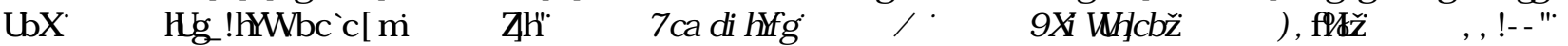

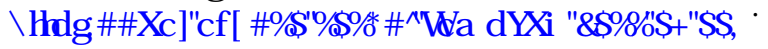

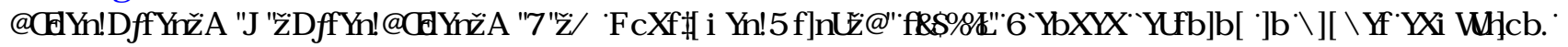

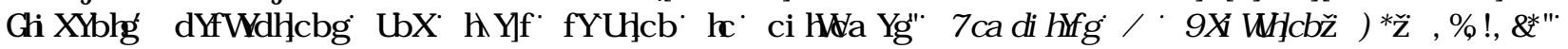

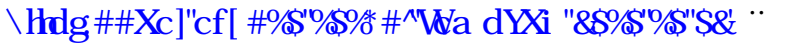

0 DQZ DU $\mathbf{m}$.

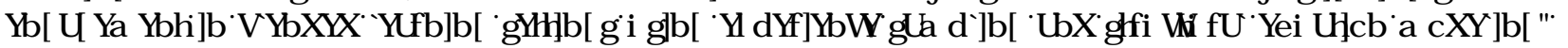

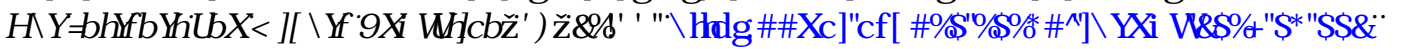

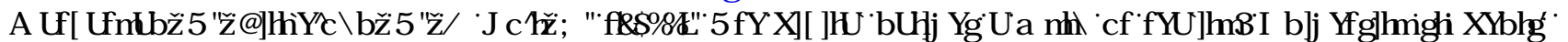

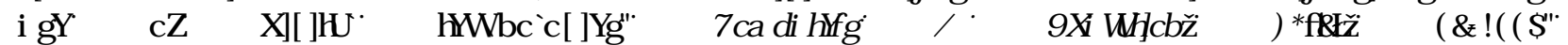
KWEm G[ GRLRY

0 LQMس6யس J DP P D ZZ KI P RWD-G]AFKDDQD

0 RRUHI-

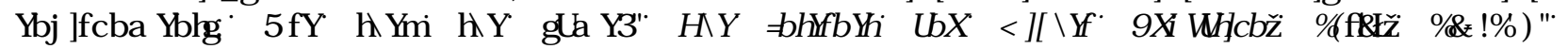

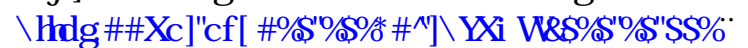

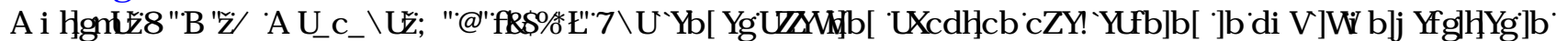

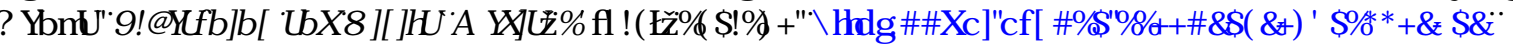

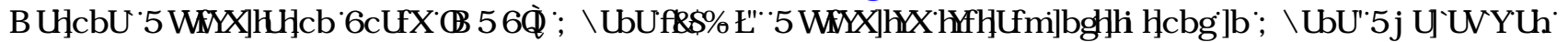

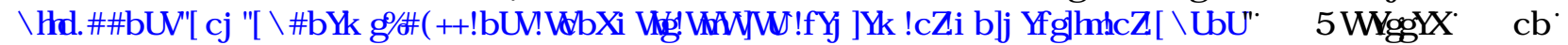

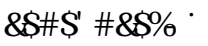

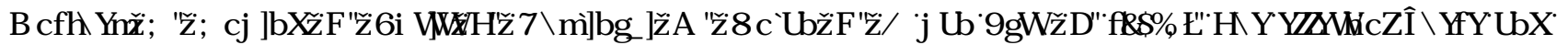

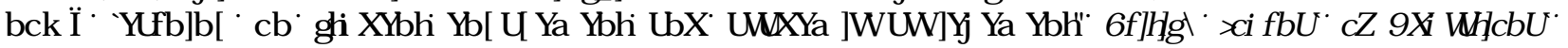

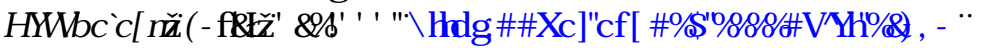




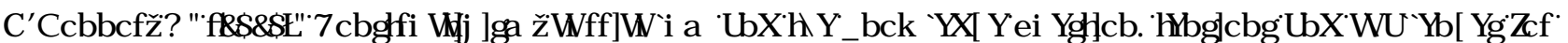

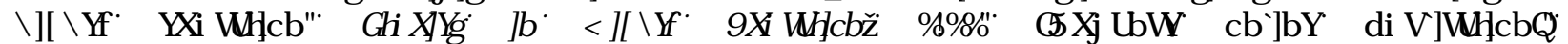
KWSVMDGRLRY

2 OYHU]

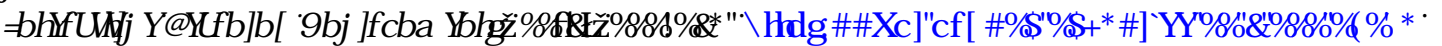

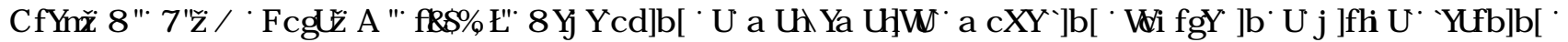

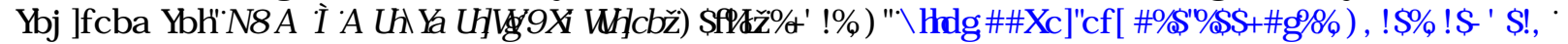

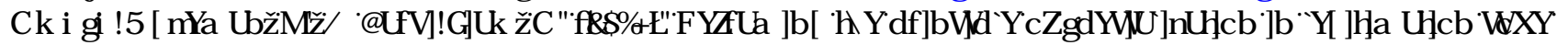

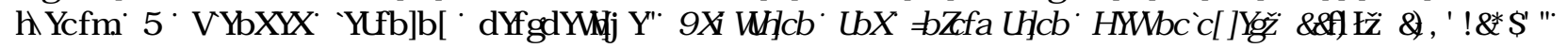

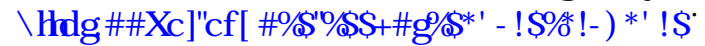

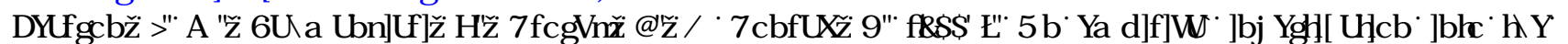

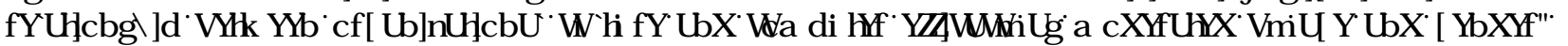

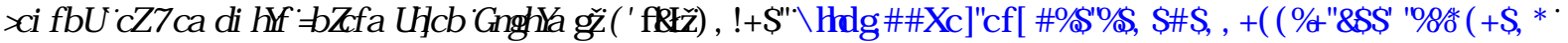

3НCDVMI

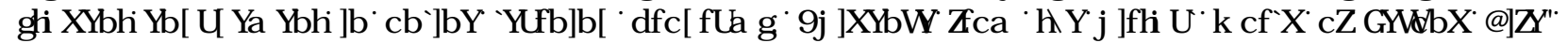

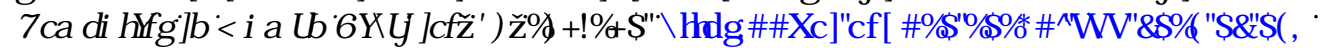

3KLOS

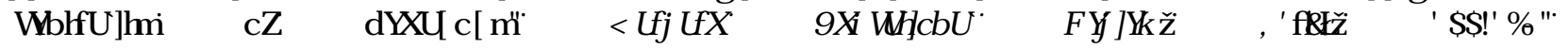

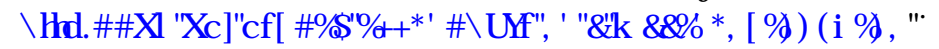

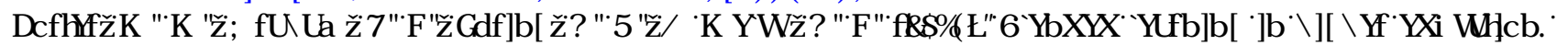

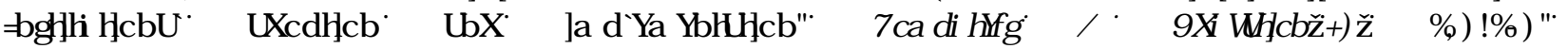

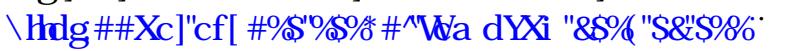

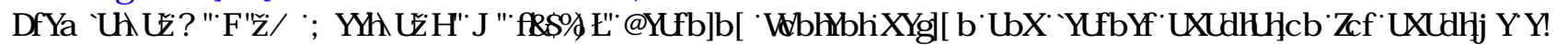

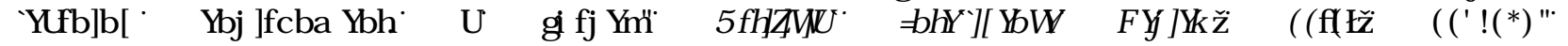

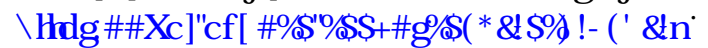

3LRNHM[\&

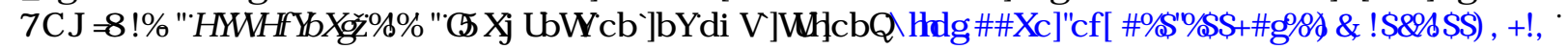

5DKLP L四( س.

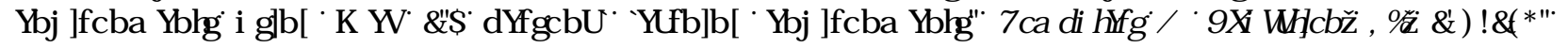

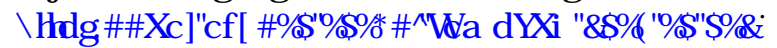

5DKLGس7m

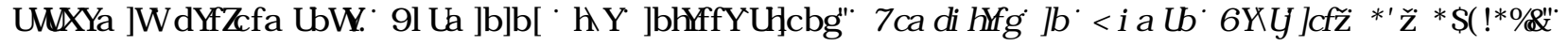
KWSVMIGRLRU

5H QD FRP P XQFFDA KWSVIDGRLIRY

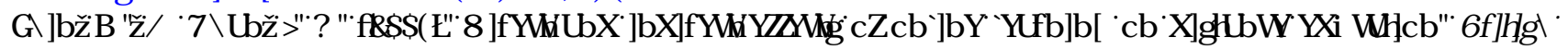

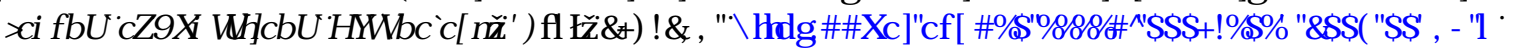

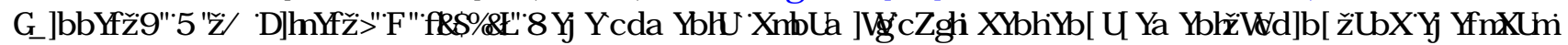

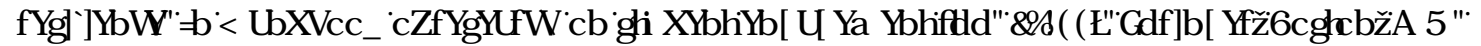

6RHDQQMR⿴囗十

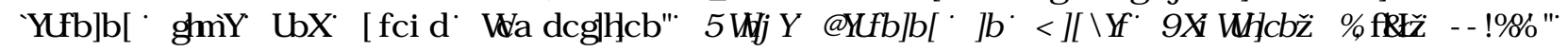
KWSVMDGRLRY

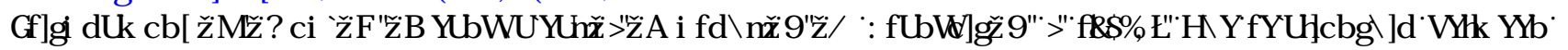

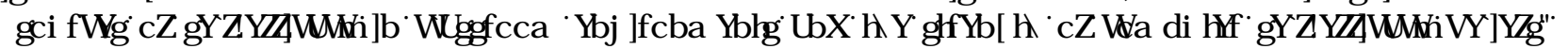

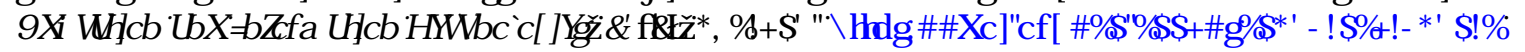

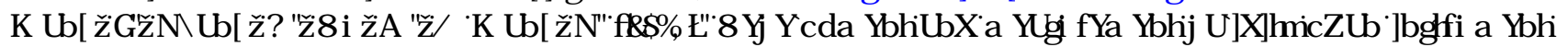

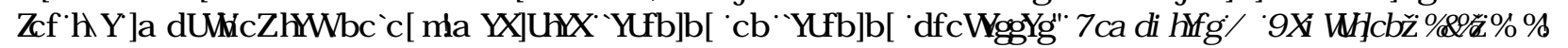

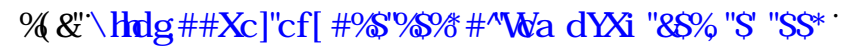

: RRGM5

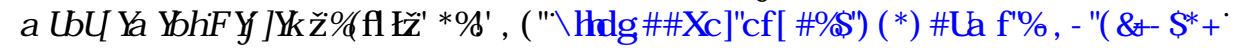

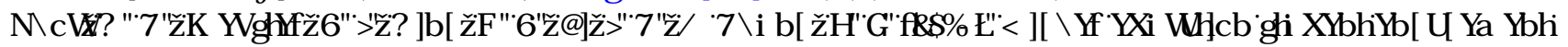

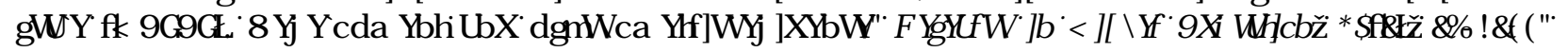

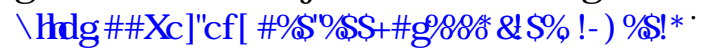

$\square$ 
Appendix 1. The student engagement and online learning instrument

\section{Engagement}

Online engagement (ENGL)

I regularly use web-based resources and information designed specifically for the course.

I regularly use email and/or other electronic means (such as WhatsApp and Facebook) to contact friends in my programme.

I regularly use the internet for study purpose

The e-learning interface is friendly and does not require detailed sign-in information.

Cognitive engagement (ENGC)

I enjoy the intellectual challenge of courses I am studying.

I derive satisfaction from studying online.

I find my courses intellectually stimulating.

I am motivated to study amidst the COVID-19 pandemic.

Social engagement with peers (ENGP)

I regularly work with other students on course areas I have problems.

I regularly get together with other students to discuss courses online.

I regularly study with other students online.

I feel part of a group of students committed to learning online.

\section{Instructional resource (INR)}

I receive frequent communication regarding new learning materials online.

The electronic learning materials that are posted online are sufficient for my use.

The online test and quizzes are regularly posted online by my lecturers

The online learning portal enhance communication between students and lecturers

The online learning portal allows for course interactivity between lecturers and students

My lecturer is able to measure my learning progress online

The learning materials posted online is up-to-date

\section{Institutional support systems and interventions (ISS)}

I receive the needed support from staff when I need technical assistance.

I find it convenient to get information on the online courses and resources from my department.

We have internet connectivity for our assignments and classroom activities on campus.

The university provides us with adequate technical support in the online learning platform.

The university has clear policies on the use of online learning platforms.

\section{Technology self-efficacy (TSE)}

I am capable of solving my computer-related problems when I am using the online learning platform.

I am very comfortable doing class work that is put online.

I am capable of using the internet to find information I need in relation to my study.

I feel confident in performing the basic functions of Microsoft Office programs (MS Word, MS Excel, and MS

PowerPoint).

I feel confident in using the Internet (Google, Yahoo) to find or gather information for online learning.

Online learning environment (ENV)

I choose a location where I study for my online courses to avoid too much distraction.

I find the online learning environment very easy to use.

I know where I can study most efficiently for my online course.

I choose a time with few distractions for studying for my online courses. 